\title{
Do Evaluative Attitudes Towards Violence Influence Violent Behaviour? A Replication and Extension
}

\author{
by \\ Lynden P. Perrault
}

A thesis submitted to the Faculty of Graduate and Postdoctoral Affairs in partial fulfillment of the requirements for the degree of

Masters of Arts

in

Psychology

Carleton University

Ottawa, Ontario

(C) 2019

Lynden P. Perrault 


\begin{abstract}
Recent research suggests that evaluative attitudes towards violence have been overlooked in forensic psychology and may be causally associated with violent behaviour (Nunes, Pedneault, \& Hermann, 2019a). The current project extended this research by experimentally testing whether manipulating evaluative attitudes towards violence would influence violent responding. Men from the community were recruited online $(N=526)$ to read convincing messages designed to make evaluations of violence more positive or more negative and complete a newly developed analogue measure of violent behaviour. The results indicated that making evaluations of violence more negative led to fewer violent responses, whereas the positive manipulation did not result in significantly more positive evaluations of violence or significantly more violent responding. The results suggest a causal relationship between negative evaluations of violence and reduced violent responding, but are inconclusive regarding more positive evaluations of violence. Potential reasons for these patterns are considered.
\end{abstract}




\section{Acknowledgements}

First, I would like to thank Dr. Kevin Nunes for his guidance, patience, and encouragement over the past two years. I am grateful for all of the time he has dedicated to providing me with valuable feedback and advice. The quality of my work has improved greatly as a result. I would also like to thank my committee members Dr. John Zelenski and Dr. Steven Prus for their feedback, expertise, and flexibility throughout this whole process. I also owe a big thank you to Etelle Bourassa and the department for being so accommodating and helpful during stressful times.

Next, I would like to thank everyone in the ACBR lab for their generosity and friendship. I am truly grateful to have been surrounded by such a supportive group of people.

Lastly, I would like to thank Mom, Dad, and Amara (and family) for all of their love and support. I couldn't have done it without you 


\section{Table of Contents}

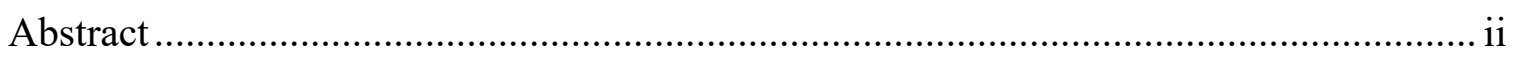

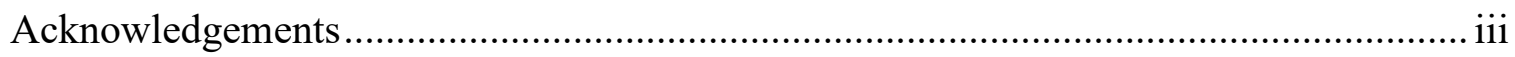

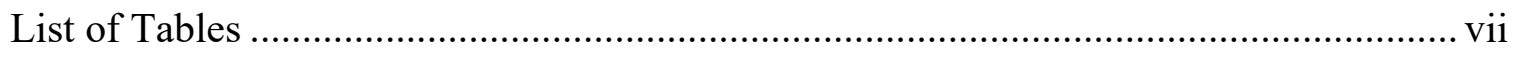

List of Figures ............................................................................................... vii

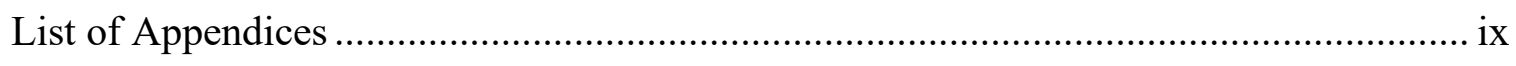

Do Evaluative Attitudes Towards Violence Influence Violent Behaviour? ...................... 1

Attitudes in the Context of Social Psychology ....................................................... 2

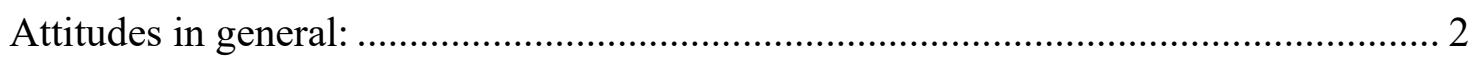

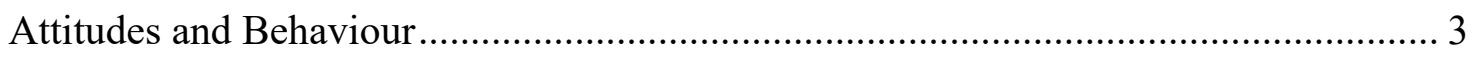

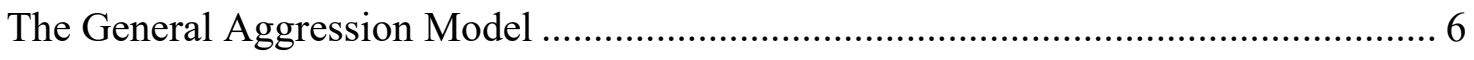

Attitudes in the Context of Forensic Psychology ........................................................... 7

A Different Approach to Attitudes.......................................................................... 8

Evaluative Attitudes and Sexual Aggression ................................................... 10

Evaluative Attitudes and Violence ..................................................................... 14

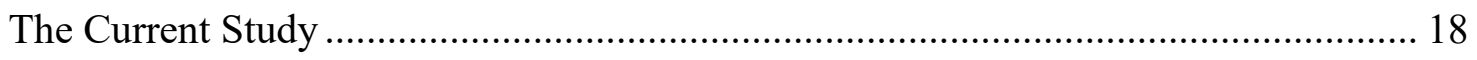

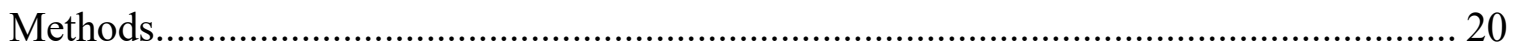

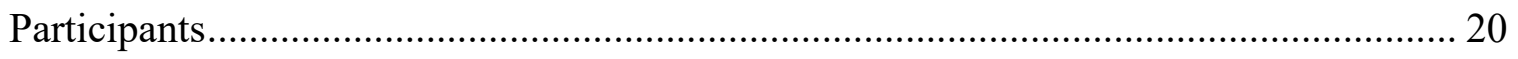

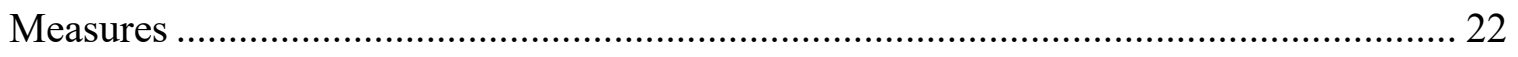

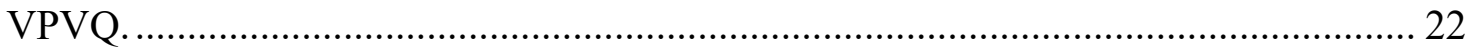

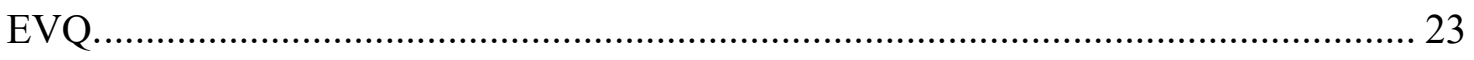

Attention and Manipulation Check Questions. .................................................. 24

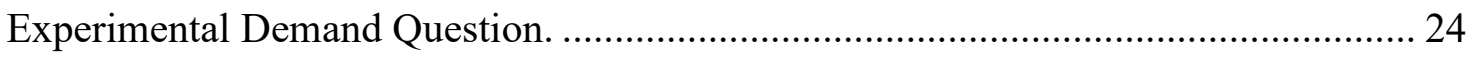




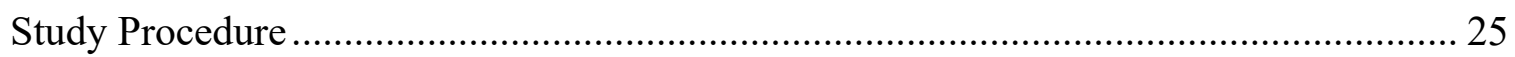

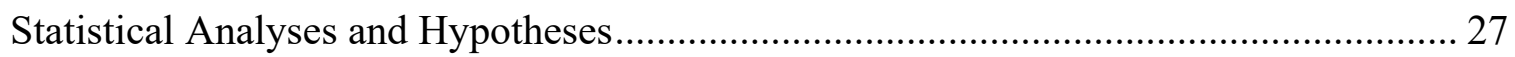

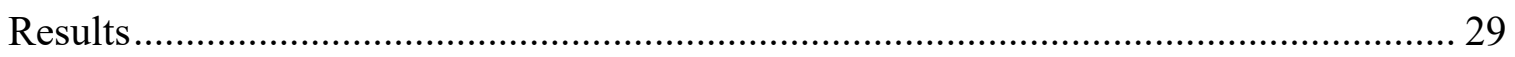

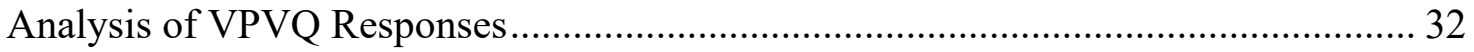

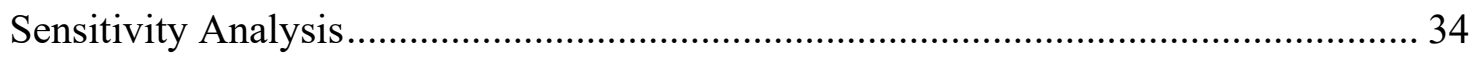

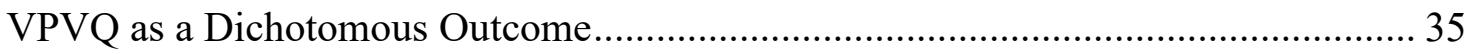

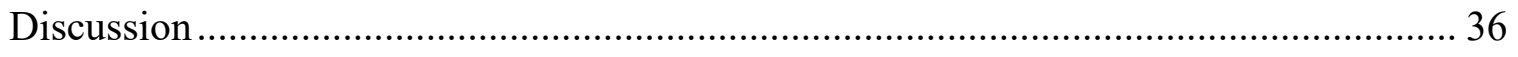

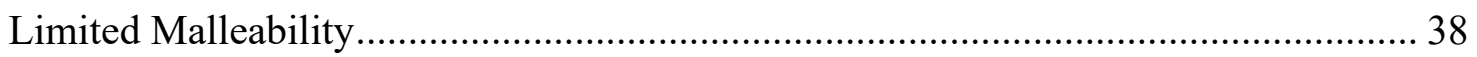

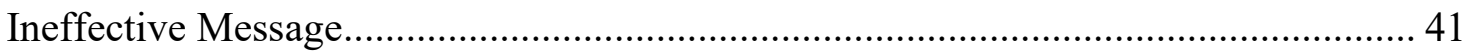

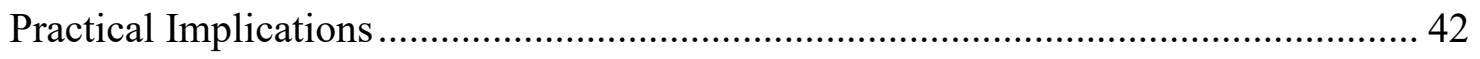

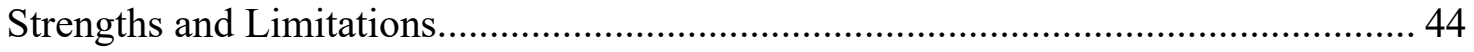

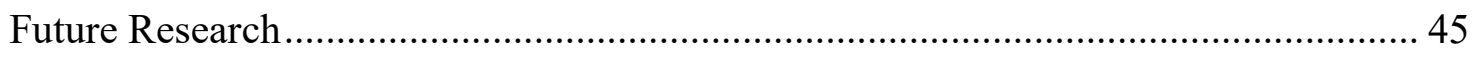

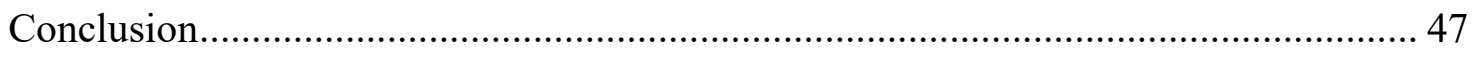

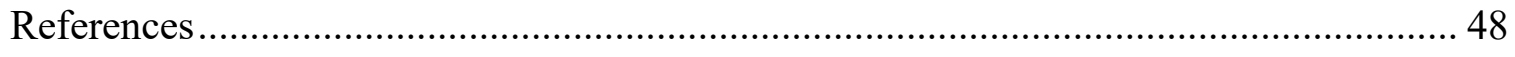

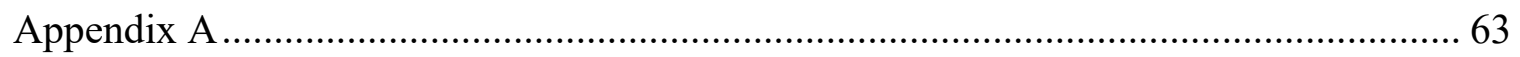

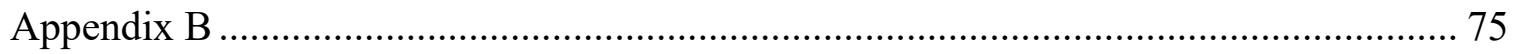

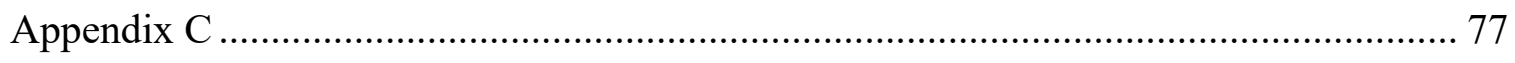

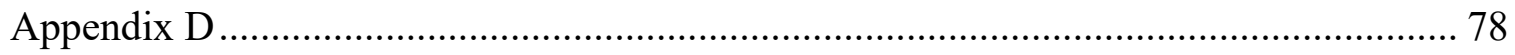

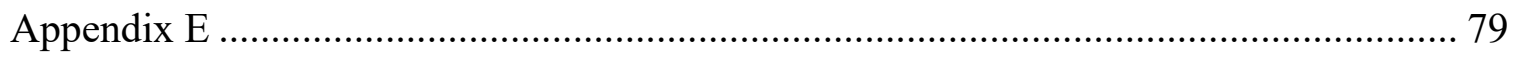

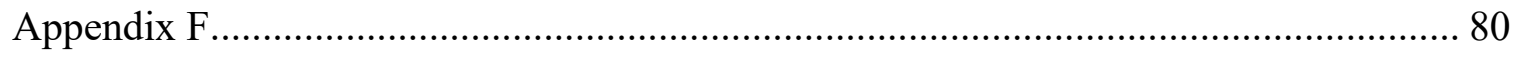

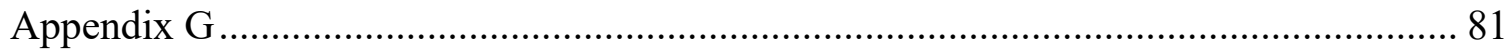

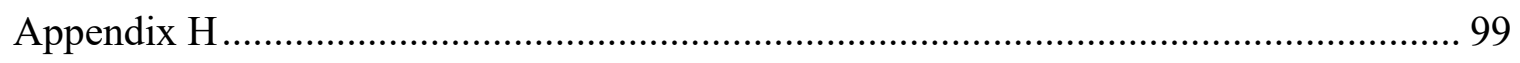

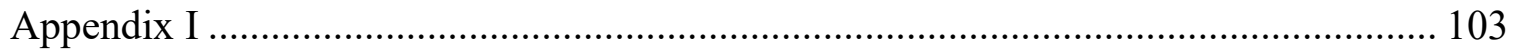




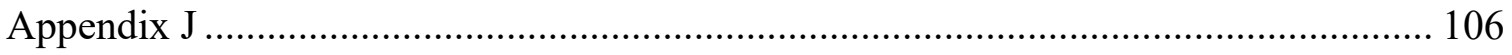

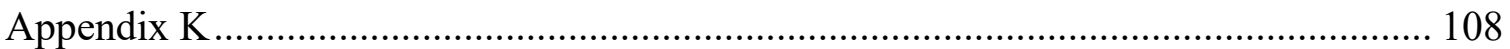

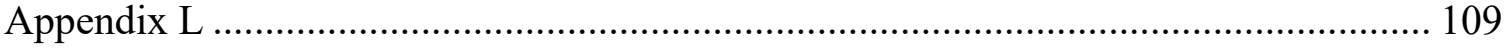

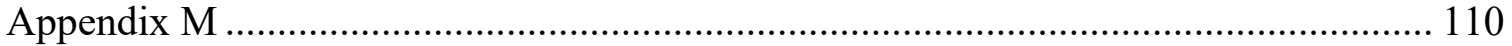




\section{List of Tables}

Table 1. Demographic Characteristics of the Sample

Table 2. Descriptive Information for the VPVQ and EVQ Collapsed

Across Conditions

Table 3. Responses to the Experimental Demand Question Within Each

Experimental Group

Table 4. Descriptive Statistics for the VPVQ by Condition

Table 5. Sensitivity Analysis Descriptive Statistics for the VPVQ by Condition

Table 6. Violent and Non-Violent Responses Across the Experimental Conditions 


\section{List of Figures}

Figure 1. Components of the Theory of Planned Behavior ............................................. 5

Figure 2. Evaluation of Violence (EVQ) scores by condition.......................................... 30 


\section{List of Appendices}

Appendix A: Violence Propensity Vignette Questionnaire (VPVQ)............ 63

Appendix B: Evaluation of Violence Questionnaire (EVQ) ................. 75

Appendix C: Attention Check Questions................................ 77

Appendix D: Manipulation Check Questions............................ 78

Appendix E: Experimental Demand Question............................ 79

Appendix F: Demographic Information.................................. $\quad 80$

Appendix G: Evaluation of Violence Manipulation...................... 81

Appendix H: Consent Form........................................... 99

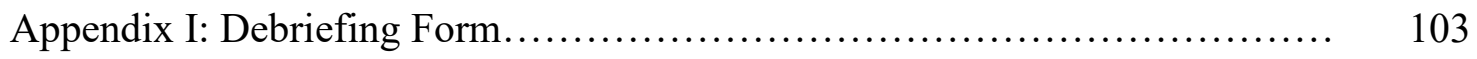

Appendix J: Mood Enhancing Photos.................................. 106

Appendix K: Descriptive Statistics for the EVQ and the VPVQ Contrasting the Entire Sample with the Men who Reported Being Attracted to Women......... 108 Appendix L: Descriptive Statistics for the EVQ and the VPVQ Contrasting the Entire Sample with the Men Who Reported Being Attracted to Women When Excluding Non-Genuine Responses............................. Appendix M: Negative Binomial Regression Analyses Only Including Men Who Reported Being Attracted to Women............................... 
Do Evaluative Attitudes Towards Violence Influence Violent Behaviour? A Replication and Extension

The consequences of violent behaviour are both familiar and shocking. Not only can victims of violence experience physical and psychological trauma (Shepherd, Shaplan, Pearce, \& Scully, 1990; Shepherd, Qureshi, Preston, \& Levers, 1990), but evidence suggests that violence is costly to all of society. For example, a report from Statistics Canada estimated that over $\$ 12$ billion in costs resulted from violent behaviour in 2009 alone, amounting to $\$ 376$ per Canadian (Hoddenbagh, Zhang, \& McDonald, 2014). Given the deleterious effects that violence can have on victims and society, there is a need to identify factors that contribute to violent behaviour.

In the field of forensic psychology, a number of factors have been identified as possible causal mechanisms for violent behaviour (Bonta \& Andrews, 2017). One factor that has recently garnered attention is evaluative attitudes towards violence (e.g., Nunes, Hermann, Maimone, \& Woods, 2015). The purpose of the current thesis is to expand on existing research regarding the role of evaluative attitudes in perpetuating violent behaviour. This thesis will begin by defining attitudes in the context of social psychology and reviewing research that connects evaluative attitudes to behaviour. A section outlining attitudes in forensic psychology will follow, providing context for an emerging line of research that addresses evaluative attitudes towards sexual aggression and violence. Lastly, details of the current experimental study exploring the causal relationship between evaluative attitudes and violence will be detailed. 


\section{Attitudes in the Context of Social Psychology}

\section{Attitudes in general:}

Attitudes have been a central focus in social psychology since the field's inception (Allport, 1935). Researchers have worked to empirically test and refine models that elucidate on the structure and function of attitudes (see Ajzen \& Fishbein, 2005; Fabrigar, MacDonald, \& Wegener, 2005; Fazio, 1990), culminating in an impressive body of knowledge. Despite the widespread study and use of attitudes, researchers still grapple with the nature and definition of attitudes. For example, some theorize that attitudes are constructed based on the consistency of internal and external cues (see Schwarz, 2007), whereas others argue that attitudes are stored in memory and can be activated in the presence of relevant stimuli (see Fazio, 2007). The one apparent similarity among different theories is that attitudes are characterized by evaluation (Conrey \& Smith, 2007; Eagly \& Chaiken, 2007; Fazio, 2007; Gawronski \& Bodenhausen, 2007; Schwarz, 2007); that is, attitudes convey some degree of positive or negative valence, appraisal, or judgement. Accordingly, one of the most widely cited definitions states that attitudes are "a psychological tendency that is expressed by evaluating a particular entity with some degree of favor or disfavor" (Eagly \& Chaiken, 1993, p.1). Therefore, attitudes encompass an evaluative tendency towards objects, ideas, people, and behaviours (e.g., Ajzen, 2001; Eagly \& Chaiken, 1993, 2007).

Recent theorizing suggests that there are two distinct classes of attitudes with differing processes responsible for evaluative responding (Gawronski \& Bodenhausen, 2006). The first, called implicit attitudes, are thought to be the product of automatic processes that result in affective reactions towards stimuli. The second, called explicit 
attitudes, are thought to be evaluations reached through propositional processes that require cognitive effort (e.g., reasoning). Implicit attitudes are often measured using response latency tasks such as the Implicit Association Test (IAT; Greenwald, McGhee, \& Schwartz, 1998), whereas explicit attitudes are commonly measured through selfreport measures such as the semantic differential (Gawronski \& Bodenhausen, 2006; Glasman \& Albarracín, 2006; Osgood, 1952; Taylor, 1971). There are multiple models that address the nature of these two processes and how they interact (e.g., Gawronski \& Bodenhausen, 2006; Petty, Briñol, \& DeMarree, 2007; Wilson, Lindsey, \& Schooler, 2000), with each receiving some degree of empirical support (e.g., Gawronski \& Bodenhausen, 2011; Petty \& Briñol, 2014; Rydell \& McConnell, 2006). Due to the scope of the current project, the terms attitude and evaluation refer exclusively to explicit attitudes unless otherwise stated.

\section{Attitudes and Behaviour}

Social psychologists have rigorously studied the behavioural implications of attitudes (see Ajzen, 2001; Ajzen \& Fishbein, 2005) and current evidence suggests that there is a moderate-to-strong attitude-behaviour relationship. For example, one metaanalysis containing 88 studies found an average correlation of .38 between attitudes and behaviour, with correlations that ranged from -.10 to .91 (Kraus, 1995). A later metaanalysis by Glasman and Albarracín (2006) bolstered these conclusions by exclusively analysing studies where attitudes were formed at the time of the experiment, controlling for many confounding variables present in prior meta-analyses. A total of 41 studies including 4,598 participants were obtained and the analysis revealed an average weighted-mean correlation of .52 between the newly formed attitudes and behaviour. 
Although the attitude-behaviour relationship was moderated by multiple variables in both meta-analyses, the overall results suggest that there is an attitude-behaviour association under various circumstances

Multiple models have been developed that elucidate on the attitude-behaviour association, with many designating attitudes as a causal determinant of behaviour. One influential model called the Theory of Planned Behavior (TPB) suggests that subjective norms, perceived behavioural control, and attitudes towards behaviour influence behavioural intentions, or the motivations to actually perform a behaviour (see Figure 1). Behavioural intentions are theorized to be the most proximal determinants of behaviour, and are therefore the last variable in the model preceding behavioural responding. Similar to the definition provided earlier, attitudes in the TPB are defined as "the degree to which a person has a favorable or unfavorable evaluation or appraisal of the behavior in question” (Ajzen, 1991, p.188) and are postulated to arise from rational processes that integrate the perceived likelihood and favourability of a behavioural outcome. This formulization, called the expectancy-value model of attitudes (see Fishbein \& Ajzen, 1975), differentiates between beliefs about the outcomes of a behaviour and the evaluations that are automatically attached to these beliefs. Both are considered precursors to attitudes and are integrated in a multiplicative fashion (i.e., the probability of an outcome is multiplied by the evaluation of the outcome), suggesting that the two concepts are interconnected but distinct. The TPB is highly regarded and has received empirical support across multiple domains of research (e.g., Ajzen 2001; Ajzen \& Fishbein 2005; Cooke, Dahdah, Norman, \& French, 2016; Kautonen, Gelderen, \& Fink, 2015; Rich, Brandes, Mullan, \& Hagger, 2015). 


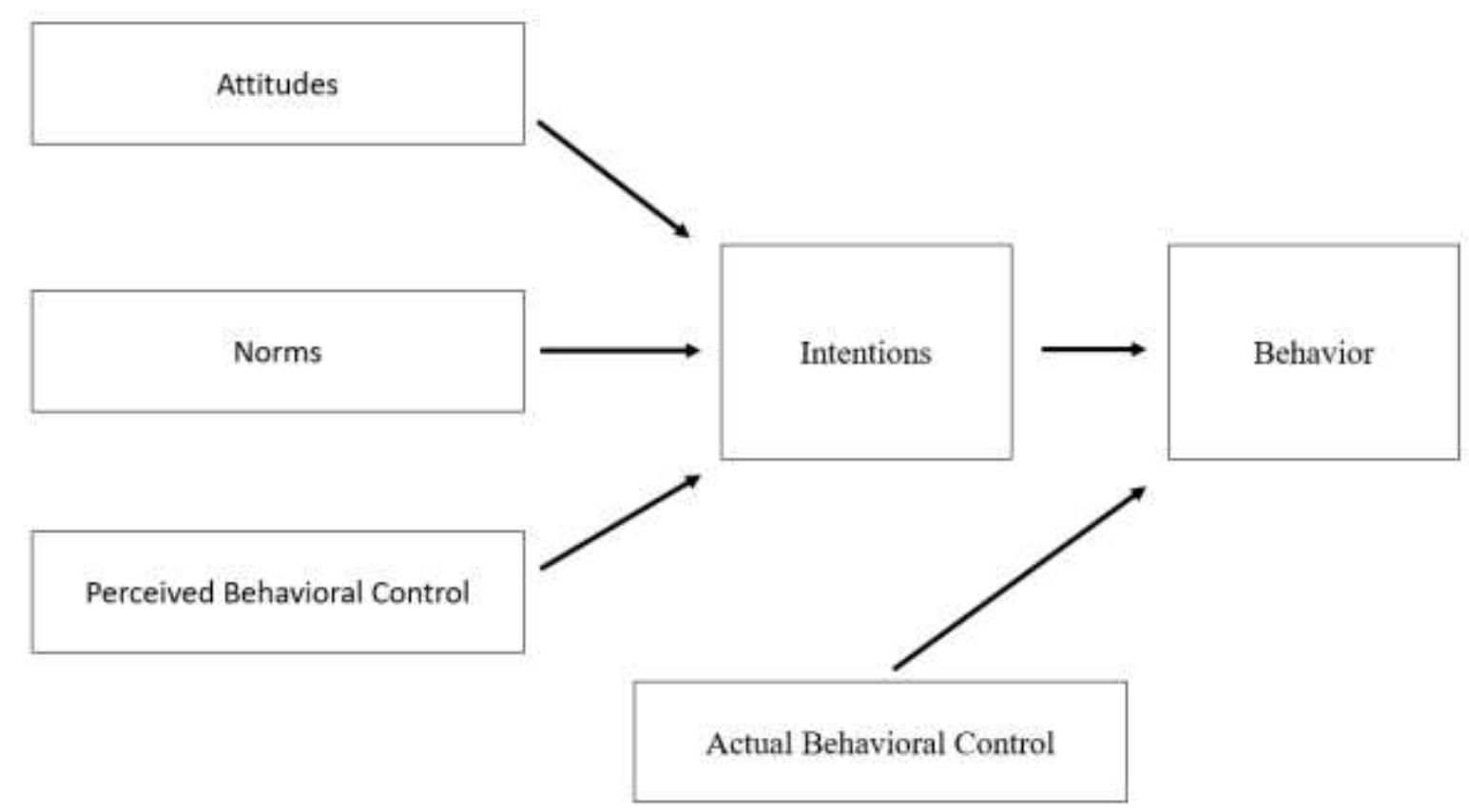

Figure 1. Components of the Theory of Planned Behavior Another framework called the Motivation and Opportunity as Determinants (MODE; Fazio, 1990) model suggests that attitudes are stored in memory as associative links between attitude objects and their corresponding evaluation. The model states that accessible attitudes, conceptualized as strong associative links between objects and their corresponding evaluations, are likely to influence behaviour through spontaneous and effortful processes. The spontaneous process influences behaviour by biasing cognitive processes and perceptual cues whereas the effortful process requires reasoning and deliberative processing. The proponents of the MODE model suggest that effortful processes are only possible when one has ample opportunity and motivation to actively process incoming information. Opportunity refers to circumstances that allow processing to take place (e.g., tasks requiring immediate reactions do not provide the opportunity for cognitively effortful responding) and motivation refers to reasons for engaging in 
effortful processing, such as the fear of making a poor or adverse choice. The MODE model therefore presents two distinct processes by which attitudes can influence behaviour.

\section{The General Aggression Model}

Various theories in psychology have aimed to accurately formulate and contextualize the processes that contribute to violent behaviour (see Bandura, 1973; Anderson \& Bushman, 2002). One of the most recent and prominent models, called the General Aggression Model (GAM; Anderson \& Bushman, 2002), is the result of an effort to integrate the strengths of these models into a cohesive framework. The GAM focuses on the sequence of factors and processes that can invoke violent responding during a social interaction. Cognitions are identified as inputs that increase one's propensity to act violently and include factors such as beliefs and attitudes. Attitudes are therefore one of many personal and situational factors that can contribute to violent responding. These cognitive inputs impact a person's internal state (i.e., thoughts, feelings, and arousal) and the subsequent automatic inferences they make about the social encounter. Informational processing then leads to either controlled or impulsive acts of violence. The controlled process occurs when one has the time and cognitive resources to reappraise the automatic inferences, resulting in a diminished (e.g., realizing the perceived provocation is accidental) or increased (e.g., realizing the provocation is targeted and intentional) inclination to act violently. Impulsive actions occur when these resources are not available. The model was recently extended to encompass specified forms of violence, such as intimate partner violence and intergroup violence (see DeWall, Anderson, \& Bushman, 2011). 


\section{Attitudes in the Context of Forensic Psychology}

Psychologists working in forensic settings are tasked with understanding, predicting, and providing treatment for various forms of criminal behaviour (Andrews, Bonta, \& Hoge, 1990; Bonta \& Andrews, 2017). Progress in this domain has been driven by empirically-validated frameworks that have identified methods and factors that aid in the rehabilitation of offenders (e.g., the risk-need-responsivity model; Bonta \& Andrews, 2017). These frameworks emphasize specialized targets for treatment called dynamic risk factors, conceptualized as risk factors that are causally related to offending and are amenable to change (Andrews, Bonta, \& Hoge, 1990; Bonta \& Andrews, 2017; Douglas \& Skeem, 2005). Dynamic risk factors are considered important in theory and practice because changes in these factors should result in equivalent changes in criminal activity, providing clinicians with mechanisms that can be targeted in therapy.

One class of dynamic risk factors that has received attention are pro-criminal attitudes. Generally defined as crime-supportive cognitions, pro-criminal attitudes encompass a wide range of thoughts and beliefs (Bonta \& Andrews, 2017). For example, some pro-criminal attitudes are derived from neutralization theory, a classic theory that describes the origin and function of many cognitions that support criminal behaviour (Sykes \& Matza, 1957). Briefly, neutralization theory suggests that lawbreakers can believe in law-abiding norms but still violate them while preserving their self-image by generating reasons for their actions. These cognitions are labeled as neutralizations and consist of justifications, excuses, and denials of wrongdoing. Examples include denying responsibility for actions (e.g., saying harmful actions were accidental or suggesting outside influences forced them to act in that way), denying that any real harm was done 
(e.g., "The property I stole is not expensive and can be easily replaced by the owners"), and justifying one's actions towards victims (e.g., "They were disrespectful towards me and deserved to be punched"). These cognitions, also commonly labeled as cognitive distortions, are associated with various forms of delinquent and anti-social behaviour (see Helmond, Overbeek, Brugman, \& Gibbs, 2014). Other categories of pro-criminal attitudes include rejections of convention and identification with criminal others (Bonta \& Andrews, 2017; Miller, 1958; Stewart, Schreck, \& Simons, 2006).

\section{A Different Approach to Attitudes}

Recent research in forensic psychology has taken a different approach towards attitudes in the context of violence and sexual aggression (e.g., Nunes et al., 2015; Nunes, Hermann, White, Pettersen, \& Bumby, 2018). Specifically, there has been an effort to delineate between the various cognitions encompassed by pro-criminal attitudes in forensic contexts and the classic definition emphasising evaluation in social psychology. As demonstrated previously, the term "attitude" in forensic contexts refers to an array of cognitions that do not appear to reflect evaluations towards criminal behaviour. This conceptualization is apparent in many measures of attitudes towards violence, such as the Violence Scale of the Measures of Criminal Attitudes and Associates (MCAA-V; Mills, Kroner, \& Forth, 2002) and Criminal Attitudes to Violence Scale (CAVS; Polaschek, Collie, \& Walkey, 2004), where items seem to reflect an assortment of cognitions (e.g., "Fighting between men is normal", "Lots of people are out to get you so you have to be violent", "Someone who makes you really angry shouldn't complain if they get hit", "People who get beat up usually had it coming", "It is reasonable to fight someone who cheated you"). Although there may be evaluative qualities to some of these items, it is not 
evident that responses to these items provide definitive information about evaluations towards violent behaviour. This is not to say that the cognitions captured by these measures are irrelevant or unworthy of further inquiry, given that the CAVS and MCAA are associated with violent and aggressive behaviour (e.g., Gilbert, Daffern, Talevski, \& Ogloff, 2013; Mills, Kroner, \& Hemmati, 2004; Polaschek et al., 2004). Rather, evaluative attitudes may be absent or a small portion of what is captured by prominent measures of attitudes towards violence, and this could be an important oversight in forensic psychology (Nunes et al., 2015).

Efforts to understand the function of evaluative attitudes in the context of criminal behaviour is important for two reasons. First, evidence from social psychology suggests that evaluative attitudes are empirically and theoretically linked to behaviour (e.g., Ajzen, 1991; Ajzen \& Fishbein, 2005; Fazio, 1990; Glasman \& Albarracín, 2006; Kraus, 1995), indicating that they may influence violent behaviour (e.g., Anderson \& Bushman, 2002). Second, researchers have noted that different cognitions may uniquely contribute to criminal behaviour in that some may be causes or consequences of the behaviour, others may strengthen or weaken the behaviour, and yet others could have little to no impact (see Maruna \& Copes, 2005; Nunes et al., 2015; Nunes et al., 2018). Conflating distinct cognitions into a single category may detrimentally affect our understanding and subsequent treatment of criminal behaviour insofar as it limits the potential for accurate and targeted assessments of different cognitions (see Maruna \& Mann, 2006; Nunes et al., 2015; Nunes et al., 2018). Therefore, research addressing the specific contributions of evaluative attitudes will refine current knowledge about violent and sexually aggressive 
behaviour and possibly improve approaches to therapy. The results from recent studies support this proposition.

\section{Evaluative Attitudes and Sexual Aggression}

Most research addressing evaluative attitudes in forensic psychology has been in the context of sexual aggression. The first of these studies explored how implicit and explicit attitudes towards rape related to self-report measure of sexual aggression (Nunes, Hermann, \& Ratcliffe, 2013). Eighty-six male undergraduate students completed the Rape Evaluation IAT, a measure of implicit attitudes towards rape, and the Rape Outcome (RO) Evaluation Scale. Because outcome expectancies are theorized to be antecedents to evaluative attitudes in the expectancy-value model of attitudes (e.g., Ajzen, 1991) this measure was included as a measure of explicit attitudes towards rape. The outcome variables included a measure of self-reported sexually coercive behaviour and a question addressing one's likelihood to rape. The results indicated that explicit and implicit attitudes were positively associated with both outcome variables $(r \mathrm{~s}>.41)$ and less negative for those who reported the most sexual aggression and likelihood to rape compared to those who reported no sexual aggression or likelihood to rape (Cohen's $d \mathbf{s}>$ 0.76). Furthermore, two logistic regressions where implicit and explicit attitude scores were entered into the same model predicted past sexually coercive behaviour and likelihood to rape better than either measure alone. Together, these analyses suggested that evaluative attitudes differentiated between sexually aggressive and non-sexually aggressive male students in the expected manner, providing preliminary evidence that evaluative attitudes are associated with sexual aggression. 
These results were extended in a later study that utilized an online sample of 150 male students and 378 community men (Hermann, Nunes, \& Maimone, 2018). Participants completed a randomly assigned subset of measures due to the large number of measures included in the study. As a result, participants completed one of two variations of the rape evaluation IAT, two of three explicit measures of evaluative attitudes towards sexually aggressive behaviour, one of two measures of rape supportive cognitions, two measures of likelihood to rape, and a self-report measure of past sexual aggression. Unlike the previous study, bivariate correlations did not reveal significant associations between the implicit measures and self-reported sexual aggression or likelihood to rape $(r s<.13)$. There were also no significant differences in implicit attitudes between those who reported histories of physical sexual aggression and those who reported no history of sexual aggression (Cohen's $d$ s $<0.18$ ). Conversely, with the exception of one measure in the student sample, explicit evaluative attitudes were positively associated with both outcome variables $(r \mathrm{~s}>.31)$ and less negative for those who reported past physical sexual aggression compared to those who reported no prior sexual aggression (Cohen's $d \mathrm{~s}>0.50$ ). The results of this study provided further evidence that explicit evaluative attitudes are associated with sexual aggression among students and men from the community.

The cross-sectional nature of the previous two studies only allowed for associative interpretations of the results, leaving the possibility that the observed effects were due to other processes (see Nunes et al., 2017). This limitation was partly addressed in a longitudinal study that tested whether evaluative attitudes are predictive of future sexual aggression (Hermann \& Nunes, 2018). The study contained two waves where 
participants completed a measure of sexually aggressive behaviour and a varied battery of evaluative attitude measures at two time points. Community men were recruited through an online panel and were assigned to complete one of four versions of the rape evaluation IAT, two of three explicit measures of evaluative attitudes towards sexual aggression, and a measure of self-reported sexually aggressive behaviour. The first wave contained 597 participants and reduced to 263 for the second wave due to attrition. The procedure was identical for both waves, with the exception that a single IAT was presented to all participants during the second wave. Participants were categorized based on their selfreported sexual aggression such that those who reported sexual aggression at wave one but not at wave two were deemed past aggressors, those who reported sexual aggression at wave two were deemed current aggressors, and those who reported no sexual aggression were classified as non-aggressors. Similar to the previous studies, current aggressors had significantly more positive explicit attitudes towards sexual aggression than non aggressors (Cohen's $d \mathbf{s}>0.40$ ), though no significant difference was found on the implicit measure (Cohen's $d=0.17$ ). Current aggressors also had more positive implicit (Cohen's $d=0.38$ ) and explicit (Cohens $d \mathrm{~s}>0.35$ ) evaluative attitudes than past aggressors. A cross-lagged panel analysis was used to test whether the measures of attitudes recorded at wave one predicted sexual aggression at wave two while controlling for past sexual aggression. The results indicated that sexually aggressive behaviour reported at wave two was significantly and independently predicted by the implicit and explicit evaluative attitudes towards sexual aggression recorded at wave one. This study provided the first evidence that evaluative attitudes towards sexual aggression are 
predictive of future sexually aggressive behaviour, bolstering the conclusions of prior cross-sectional studies.

Despite the associative and predictive evidence provided by these studies, there was no direct evidence that evaluative attitudes were distinct from other commonly measured cognitions in forensic psychology. This distinction was assessed in a study that included 660 male undergraduate students (Nunes et al., 2018). Participants completed semantic differential scales assessing evaluations towards rape, a common measure of rape-supportive cognitions (the RAPE scale; Bumby, 1996), a self-report measure of past sexually aggressive behaviour, and a question addressing one's likelihood to rape. The researchers first conducted an exploratory factor analysis (EFA) to determine whether the items from the semantic differential scale and the items from the RAPE scale loaded onto different factors. The EFA indicated that two factors emerged, one containing the semantical differential items and the other containing the RAPE scale items. The two factors were positively correlated $(r=.46, p<.05)$, but distinct. Next, two hierarchical regression analyses were conducted where scores from the RAPE scale were entered into the first step and evaluative attitudes towards rape were entered into the second step. Self-reported sexually aggressive behaviour was the outcome variable for the first analysis and self-reported likelihood to rape was the outcome variable for the second analysis. Both analyses indicated that evaluative attitudes independently predicted both outcome variables and accounted for a significant amount of variance above what was accounted for by the RAPE scale. Therefore, evaluative attitudes formed a separate factor from other rape-supportive cognitions and were independently associated with selfreported sexual aggression and likelihood to rape. Together, these studies provide 
evidence that evaluative attitudes towards sexual aggression are associated with sexual aggression and distinct from other cognitions commonly measured in forensic psychology.

\section{Evaluative Attitudes and Violence}

A total of eight studies have included evaluative attitudes towards violence as an independent measure. Four of these studies did not include violent behaviour as an outcome variable and were preliminary in nature. Archer (2004) examined the association between a measure of trait aggression and various semantic differential scales measuring evaluations of "aggression”, "argument", “violence”, and "fighting”. The only significant association was between evaluations of argument and a measure of verbal aggression, whereas the associations between trait physical aggression and evaluations of violence and fighting were near-zero and non-significant. Snowden, Gray, Smith, Morris, and MacCulloch (2004) compared a group of offenders convicted of murder with a group of offenders convicted of other offences on semantic differential scales and feeling thermometers measuring the favourability of "violence" and "peace". Offenders in each group were further categorized based on their scores on a measure of psychopathy (i.e., low, medium, high). No significant differences emerged between offender groups and the trend in the data suggested that offenders convicted of murder with high psychopathy scores had less favorable attitudes towards violence than did offenders convicted of other crimes with high psychopathy scores. Polaschek, Bell, Calvert, \& Takarangi (2010) administered Visual Analogue Scales (VAS) to determine whether evaluations of "violence" and "weapons" were associated with risk for recidivism among a group of male violent offenders. All associations between VAS scales and risk for recidivism were 
non-significant. Lastly, Bluemke \& Zumbach (2012) assessed trait aggressiveness and two measures of implicit aggressiveness among an online sample who were categorized as being violent video game players, non-violent video game players, and non-gamers. Violent video game players reported more trait physical aggressiveness and hostility relative to the control group, but no differences emerged between any of the groups on the implicit measures. Correlation analyses revealed a marginally significant association between implicit aggressiveness and trait physical aggressiveness, and a significant association between aggressive self-concept (i.e., the second implicit measure) and physical aggressiveness. Both correlations suggested that less negative implicit evaluations of violence were associated with increased trait physical aggressiveness.

Two additional studies that included violent behaviour as an outcome variable produced mixed results. Coccaro, Fanning, and Lee (2017) assessed participants' evaluations towards socially acceptable, overtly aggressive, and relationally aggressive responses to ambiguous situations that could be construed as provoking. Participants also completed questionnaires regarding prior aggressive behaviour, trait aggression, and relational aggression. Correlation analyses indicated that evaluations of each response type (i.e., socially acceptable, overtly aggressive, and relationally aggressive) were not significantly associated with prior aggressive behaviour $(r<.19)$, but that evaluations of overt and relationally aggressive responses were associated with trait aggression $(r s=.40$ and .22 , respectively) and relational aggression ( $r s=.22$ and .34 , respectively). Blumenthal et al. (2019) assessed how implicit evaluations related to self-reported violence and prior convictions among a sample of male offenders with diagnoses of personality disorder. Each participant was exposed to three different IATs designed to 
assess valence ("good” versus "bad), hedonic value (“enjoy” versus “dislike”), and arousal ("exciting" vs "boring") regarding violence. The sample was further split into a homicidal group (i.e., those convicted of murder or attempted murder) and a nonhomicidal group for the main analysis. Correlation analyses revealed that all three IATs were not significantly associated with violent convictions. The hedonism IAT was significantly associated with prior convictions and juvenile convictions for the nonhomicidal group ( $r s=.29$ and .40 , respectively), whereas the arousal IAT was positively associated with self-reported violence for the non-homicidal group and negatively associated with juvenile convictions for the homicidal group $(r s=.29$ and -.29 , respectively). The valence IAT was not significantly associated with any of the outcomes $(r s<.10)$.

The last two studies that directly assessed the relationship between evaluative attitudes and violent behaviour produced more promising results. Nunes et al. (2015) explored whether evaluations towards violence were independently associated with violence and distinct from two scales commonly used to assess attitudes towards violence. A sample of 568 undergraduate students (female $=76.20 \%$ ) were asked to complete the CAVS (Polachek et al., 2004), the Violence Scale of the Revised Measures of Criminal Attitudes and Associates (MCAA-R-V; Mills \& Kroner, 2007), self-reported violent behaviour, and semantic differential scales assessing evaluations towards violence, violent people, and identification of self as violent. To determine whether evaluative attitudes were distinct from the other measures, two EFAs were conducted. The first EFA examined whether the semantic differential scales were distinct from the MCAA-R-V, and the second EFA examined whether the semantic differential scales 
were distinct from the CAVS. Four positively correlated factors emerged in both EFAs, where the three semantic differential scales formed distinct factors from the MCAA-R-V and CAVS, respectively. The researchers followed this analysis with two hierarchical multiple regression analyses that included self-reported violent behaviour as the outcome variable. The first analysis entered the MCAA-R-V into the first step and the second analysis entered the CAVS into the first step. This was followed by evaluations of violence, evaluations of violent people, and identification of self as violent into the next three steps. The results indicated that all scales, except for the evaluations of violent people, independently predicted self-reported violent behaviour in both analyses. These results suggest that evaluative attitudes regarding violence are conceptually distinct from common measures of attitudes towards violence and are independently associated with violent behaviour.

Further support was found in a recent study that explored how experimentally manipulated changes in attitudes influenced responding on an analogue measure of violent behaviour (Nunes, Pedneault, \& Hermann, 2019a). A controlled randomized experiment exposed an online panel of 285 community men to either a control condition or an anti-violence condition designed to make attitudes towards violence more negative. The anti-violence condition began by defining violent behaviour and stating that violence is often unnecessary and causes many problems. Participants were then presented with a scenario that portrayed an impulsive act of violence against a man who slighted the participant, contextualizing the violence as being rooted in anger. The participant was then asked to read a convincing message containing five statements with accompanying photos that outlined the negative outcomes of acting violently, such as physical injury, 
going to prison, and escalations of violence. In contrast, those randomly assigned to the control condition were asked to imagine what they could learn while on a visit to the Grand Canyon, followed by a series of facts and photos depicting the Grand Canyon. Participants then completed an analogue measure of violence called the Violence Propensity Vignette Questionnaire (VPVQ; Nunes, Hermann, Maimone, Atlas, \& Grant, 2019) that presents ten provoking vignettes, each containing 9 possible response options that are either violent or non-violent. This was followed by a newly developed measure of evaluations towards violence called the Evaluation of Violence Questionnaire (EVQ; Nunes, Pedneault, \& Hermann, 2019b) that presents a series of violent actions and requires participants to rate the favourability of each action. The results indicated that those exposed to the negative attitude condition had significantly fewer violent responses on the analogue measure of violent behaviour (VPVQ; Cohen's $d=-0.23$ ) than those in the control condition. Furthermore, responses on the EVQ were strongly positively correlated with violent responding on the VPVQ $(r=.62)$. Together, these two studies provide evidence that evaluative attitudes are indeed associated with, and perhaps causally related to, violent behaviour.

\section{The Current Study}

The research reviewed above suggests that evaluative attitudes towards criminal behaviour have been largely overlooked in forensic psychology. To date, Nunes et al. (2019a) is the only experimental study to explore the relationship between evaluative attitudes and criminal behaviour. This may be surprising given that highly controlled experimental studies are an important step in establishing causal relationships between variables (see Nunes et al., 2019), but a look at the broader literature on pro-criminal 
attitudes suggests that this is not unusual. Few studies have explicitly examined the causal dynamic nature of pro-criminal attitudes (see Banse, Kroppehele-Gossel, Kistemaker, Werner \& Schmidt, 2013; Serin, Lloyd, Helmus, Derkzen, \& Luong, 2013), and many offender treatment studies have failed to find lower recidivism rates among offenders with reduced pro-criminal attitudes (e.g., Howard \& Doorn, 2018; Kroner \& Yessinw, 2013; Wakeling, Beech, \& Freemantle, 2013; Wilkinson, 2005; see also Banse et al., 2013). This suggests that there is a need for additional experimental studies to refine theory and establish the causal dynamic nature of specified cognitions. Although the majority of evidence is derived from research on sexual aggression, the results from Nunes et al. (2015) and Nunes et al. (2019a) suggest that evaluative attitudes towards violence may be an important contributor to violent behaviour.

As such, the purpose of the current thesis is to replicate and extend the findings from Nunes et al. (2019a) experimental study. In addition to the neutral and negative attitude conditions, the current study will add a pro-violence condition to determine whether attitudes altered to be more positive will increase the number of violent responses on the analogue measure of violent behaviour. This will allow for a complete test of whether evaluative attitudes towards violence are dynamic in nature. Replicating and extending the study will strengthen the conclusions of Nunes et al. (2019a) and provide further evidence that evaluations of violence influence violent responding.

Like Nunes et al. (2019a), the current study will use convincing messages to alter participants' evaluations towards violence. Convincing messages are an established attitude change procedure that have been used to successfully change attitudes towards comprehensive exams (e.g., Johnson, 1994; Leippe \& Elkin, 1987; Petty, Cacioppo, \& 
Goldman, 1981), affirmative action and cellphone use in class (Park, Levine, Westerman, Orfgen, \& Foregger, 2007), career choice (Strader \& Katz, 1990), and violent behaviour (Nunes et al., 2019b). The pro-violence attitude change condition in the present study will expose participants to a convincing message that details the benefits of defending oneself in a threatening situation, highlighting the admirable, heroic, and honourable aspects of violence in this context. It is hypothesized that, like Nunes et al. (2019a), participants exposed to the negative attitude condition will respond less violently on the analogue measure of violence relative to those in the neutral condition. Conversely, those exposed to the positive attitude condition are hypothesized to respond more violently than those in the neutral and negative conditions. Results supporting these hypotheses will suggest that evaluative attitudes towards violence are causally related to violent behaviour.

\section{Methods}

\section{Participants}

An online sample of community men were recruited by an online panel service (Qualtrics Panel; Qualtrics, 2014) to complete the survey and receive a monetary reward for their time. The sample was limited to North American men primarily between the ages of 18 and 40 . These criteria were selected because the measures in this project are tailored towards men (e.g., references to other men attempting to seduce the participant's girlfriend or wife) and to reflect the age range of characteristically antisocial males (see Hermann \& Nunes, 2018; Stolzenberg \& D’Alessio, 2008). Seventy-six potential participants were screened out prior to the start of the study because they were not male $(n=33), 18$ years of age or older $(n=16)$, from the US or Canada $(n=4)$, or fluent in English $(n=23)$. A further 258 participants withdrew during the course of the study and 
189 others were screened out for failing manipulation checks $(n=132)$ or speeding through the study $(n=57)$.

Table 1

Demographic Characteristics of the Sample

\begin{tabular}{lc}
\hline & Community Men $(N=526)$ \\
\cline { 2 - 2 } Demographic Characteristics & $\%(\mathrm{n})$ \\
\hline Age & \\
$18-20$ & $13.1(69)$ \\
$21-25$ & $22.4(118)$ \\
$26-30$ & $30.2(159)$ \\
$31-35$ & $10.6(56)$ \\
$36-40$ & $8.6(45)$ \\
$41-50$ & $9.7(51)$ \\
$51-60$ & $1.9(10)$ \\
61 or Older & $3.4(18)$ \\
Country & \\
Canada & $49.8(262)$ \\
United States & $50.2(264)$ \\
Relationship Status & \\
Single & \\
In a Romantic Relationship & $48.1(253)$ \\
Living with Romantic Partner & $10.3(54)$ \\
Married & $12.2(64)$ \\
Separated & $25.9(136)$ \\
Sexually Attracted to & $3.6(19)$ \\
Women & \\
Men & $87.6(461)$ \\
Women and Men Equally & $4.0(37)$ \\
Other & $0.4(2)$ \\
\hline
\end{tabular}


Of the 546 remaining participants, 19 were missing data on at least one of the two primary measures (Evaluation Violence Questionnaire [EVQ], $2.2 \%, n=12$; Violence Propensity Vignette Questionnaire [VPVQ], $1.3 \%, n=7)$. Little's MCAR test was employed to determine whether the data were missing completely at random, and was found to be non-significant, $\chi^{2}(414)=365.38, p=.96$. Therefore, listwise deletion was used for all further analyses. One further participant was excluded due to providing uncharacteristically extreme scores on both measures, resulting in a total sample size of 526 community men. All demographic information was collected via categorical response options and can be found in Table 1. The majority of participants indicated they were between the ages of 21 and $30(52.6 \%, n=277)$, from the United States $(50.2 \%, n=$ $264)$, not in a romantic relationship $(48.1 \%, n=253)$, and sexually attracted to women $(87.6 \%, n=461)$.

\section{Measures}

VPVQ. The VPVQ (Nunes et al., 2019) is a self-report measure that utilizes a series of ten vignettes to assess male's current propensity for violence (see Appendix A). Each vignette contains two rounds. The first round presents a provoking situation (e.g., "A man cuts in front of you in a line", "A man tries to 'pick up' your girlfriend/wife right in front of you") and asks the participant to select a response option that reflects how they would actually react in that situation. A total of nine possible response options are provided that are either violent (e.g., hit him, shove him) or non-violent (e.g., insult him, joke about it, ignore it). After an action is chosen, a follow-up scenario is presented based on the participant's previous response, and they are again asked how they would react with the same array of response options. A point is given if a violent response is selected 
in either round of each vignette. A total score is computed by summing the number of points across the ten vignettes, resulting in a score that can range from 0 to 10 . Nunes et al. (2019) demonstrated that violent responses on the VPVQ are associated with higher self-reported physical aggression and retrospective violent behaviour for male undergraduate students and males from the community. Incarcerated males displayed similar results with an additional positive association between VPVQ scores and risk of recidivism but no significant associations were found between VPVQ scores and violent convictions. The VPVQ demonstrated acceptable reliability for the community men $($ Cronbach's alpha $=.82)$ and the incarcerated men $($ Cronbach's alpha $=.82)$.

EVQ. The EVQ (Nunes et al., 2019b) is a self-report measure assessing evaluative attitudes towards violence (see Appendix B). The measure contains 17 items that present a violent action (e.g., "You hitting [for example, punching or kicking] a guy who hurts someone you care about") and participants are asked to rate how negative vs positive, unpleasant vs pleasant, or bad vs good the action is on a four-point scale (e.g., very negative, a bit negative, a bit positive, very positive). Total scores are computed by averaging all of the responses, resulting in a score that can range from one to four, with higher scores reflecting more positive evaluations of violence. Little research has been conducted using the EVQ, but Nunes et al. (2019b) found acceptable reliability $($ Cronbach's alphas $=.95, .96)$ and evidence of construct validity in an online sample of men from the community. Specifically, Nunes et al. (2019) found that responses to the EVQ were more negative for men who viewed an anti-violence message rather than a neutral message prior to completing the measure. Scores on the EVQ were also lower than baseline EVQ scores when the measure was administered before and after the anti- 
violence message, providing evidence that the measure is sensitive to within-person changes in evaluative attitudes.

Attention and Manipulation Check Questions. Two attention check questions were presented during administration of the EVQ. Each question asked participants to select a specific answer (e.g., "Please select 'a bit unfavourable""; see Appendix C) and were randomized so that each question appeared in a different position for each participant. Three manipulation check questions were presented following the EVQ to test whether participants attended to the experimental manipulation. For each question, participants were asked to select which message they had seen at the beginning of the survey and were provided with three options that briefly summarized segments from each of the conditions (e.g., "(a) The Grand Canyon is considered to be one of the seven wonders of the natural world. (b) Violence can lead to you getting arrested, getting a criminal record, and going to prison. (c) Using violence can defend you and people you care about from getting injured by an attacker."; see Appendix D). Therefore, those who were randomly assigned to the anti-violence condition needed to select " $b$ " to correctly answer the question, whereas those assigned to the pro-violence condition needed to select "c" to correctly answer the question.

Experimental Demand Question. A question addressing whether participants believed the experimental manipulation had a genuine effect on their responses was included as a test of experimental demand (Appendix E). Three response options were presented. The first indicated the manipulation had a genuine effect ("The message changed how I answered and it changed how I really think about violence), the second indicated the manipulation had a non-genuine effect ("The message changed how I 
answered, but it didn't change how I really think about violence"), and the third indicating the manipulation had no effect on their responses ("The message didn't change how I answered"). The question was best suited to those in the pro-violence and antiviolence condition given that the neutral condition was not designed to have an effect on evaluations of violence.

\section{Study Procedure}

The Qualtrics survey began with a consent form and a message asking whether the person agreed to complete the study (Appendix H). Those who agreed were directed to a demographic/screening questionnaire that contained questions about the participants age, sex, relationship status, sexual preference, country of residence, and English fluency (Appendix F). Those who did not meet the eligibility criteria (i.e., male, 18 or older, from the US or Canada, fluent in English) were notified that they did not meet the inclusion criteria and were directed out of the study. Participants who met the inclusion criteria were linked to the main study where they were randomly assigned to either a proviolence condition (to make evaluations of violence more positive), an anti-violence condition (to make evaluations of violence more negative), or a control condition (see Appendix G). The anti-violence and the control conditions were the exact same as those from Nunes et al. (2019a), described in the introduction. The positive attitude condition had a near identical structure to the negative attitude condition, but included different content. The condition began by defining violent behaviour and stating that violence is sometimes necessary. This was followed by a written passage that depicted a provoking scenario (i.e., asking the participant to imagine an unknown man approaching and attacking him and an important woman in his life), creating a situation where self-defence 
would be justifiable. The participant was then exposed to five convincing messages that outlined the positive outcomes of acting violently (e.g., "You keep you and the woman from getting serious injuries"), with accompanying pictures that portrayed violence as heroic, honourable, and admirable.

After exposure to one of the three conditions, participants completed the VPVQ as an analogue measure of violent behaviour. A single vignette appeared on screen at a time and the order of presentation was randomized for each participant. Participants then completed the EVQ to test whether the expected attitude changes occurred in each of the respective conditions. Two attention check questions were presented during the administration of the EVQ. The two questions were programmed so that participants who incorrectly answered both attention check questions were automatically screened out of the survey. The EVQ and attention check questions were presented simultaneously on a single page and the order of the questions were randomized for each participant. This was followed by three manipulation check questions designed to assess whether participants attended to the experimental manipulation. Like the attention check, participants were automatically screened out if they failed two or more of the manipulation check questions and were not permitted to finish the survey. Lastly, the experimental demand question was presented to assess whether participants believed their answers to the VPVQ were affected by the manipulation.

The last section of the study contained different stimuli depending on which condition the participant was randomly assigned to. Those who were assigned to the proviolence condition were presented with the anti-violence condition to "undo" the effects of the pro-violence condition, followed by a series of 12 nature photos to enhance mood 
(Appendix J), and the debriefing form (Appendix I). Those who were assigned to the anti-violence or control conditions were directed straight to the nature photos and then the debriefing form. These two different paths were also implemented for those who failed the attention/manipulation check questions or withdrew from the study.

\section{Statistical Analyses and Hypotheses}

The first analysis addressed whether the experimental manipulation had the desired effect on evaluations of violence. Specifically, a one-way ANOVA was conducted to compare EVQ scores across the three experimental conditions. It was hypothesized that those in the anti-violence condition would have lower EVQ scores than those in the neutral and pro-violence condition, whereas those in the pro-violence condition would have higher EVQ scores than those in the neutral condition. An exploratory chi-square test of independence was also conducted on the experimental demand question. There were no a priori hypotheses for this analysis.

The main analysis addressed whether the rate of violent responding on the VPVQ differed between experimental groups. It was hypothesized that those in the anti-violence condition would have fewer violent responses than those in the neutral or pro-violence conditions, whereas those in the pro-violence condition would have more violent responses than those in the neutral condition. The VPVQ provides count data (i.e., nonnegative integers reflecting the number of violent responses selected) that are positively skewed with scores primarily concentrated between zero and four violent responses. The Poisson family of regression models are optimal for analyzing count data with arithmetic means lower than 10 (see Coxe, West, \& Aiken, 2009), and were therefore the analysis of choice in the current project. An important assumption of the standard Poisson regression 
is that the conditional mean and variance are equal. When this assumption is violated, the data are said to be "overdispersed" and can lead to inflated test statistics (Coxe, West, \& Aiken, 2009). When this occurs, it is advisable to conduct a negative binomial regression rather than a standard Poisson regression. Negative binomial models include an ancillary parameter that accounts for additional variance in the data, providing estimates of the standard error that do not lead to inflated test statistics (Coxe, West, \& Aiken, 2009). This assumption can be tested by setting the ancillary parameter of a negative binomial model to zero (the equivalent of a standard Poisson model) and running the Lagrange multiplier test. A significant result indicates that the ancillary parameter is not zero and that a negative binomial model provides a better fit for the data. Akaike's Information Criterion (AIC) and Bayesian Information Criterion (BIC) are also useful when determining model fit. These two fit statistics are presented in smaller-is-better form, such that the better fitting model produces lower AIC and BIC values (see Coxe, West, \& Aiken, 2009).

As a supplement to the main analysis, the VPVQ was analyzed as a dichotomous outcome variable. Each participant was coded as having either no violent responses or as having one or more violent responses on the VPVQ. A series of phi coefficients were then calculated between each experimental condition and the dichotomous outcome. It was hypothesized that the associations would match the results of the primary analysis such that there would be two significant negative associations (i.e., neutral and antiviolence condition, pro-violence and anti-violence condition) and one significant positive association (i.e., neutral and pro-violence condition). 


\section{Results}

Descriptive information for the EVQ and VPVQ collapsed across experimental conditions are presented in Table 2. Pearson's correlation indicated that the measures were strongly positively correlated and corresponded with a large effect size (see Cohen, 1992), $r=.56, p<.001$. Two analyses were conducted to examine whether the experimental manipulation had the desired effect on evaluations towards violence. First, a one-way ANOVA was utilized to determine whether EVQ scores differed between the pro-violence $(n=175)$, anti-violence $(n=175)$, and neutral conditions $(n=176)$.

Descriptive information can be found in Figure 2. Levene's test of equality of error variances indicated that the homogeneity of variance assumption was violated, $F(2,523)$ $=3.34, p=.036$, but the results of the Welch test and standard ANOVA were nearly identical; therefore, the results of the standard ANOVA are reported. The one-way ANOVA revealed a significant effect, $F(2,484)=6.75, M S E=.45, p=.001$, and the Games-Howell post hoc procedure was selected to determine the differences between the groups. Participants in the anti-violence condition had significantly lower EVQ scores than those in the neutral condition, $\mathrm{p}=.001, d=-0.33,95 \% \mathrm{CI}[-0.54,-0.12]$ and the proviolence condition, $p=.01, d=-0.30,95 \%$ CI [-0.51, -0.09$]$, whereas no significant difference emerged between the pro-violence and neutral conditions, $p=.85, d=-0.06$, $95 \%$ CI $[-0.27,0.15]$. Together, these results suggest that the anti-violence manipulation successfully induced more negative evaluations of violence, whereas the pro-violence condition did not induce more positive evaluations of violence. In fact, the pro-violence EVQ scores trended towards being more negative than the EVQ scores in the neutral condition. 
Table 2

Descriptive Information for the VPVQ and EVQ Collapsed Across Conditions

\begin{tabular}{lccccc}
\hline Measure & $M$ & $S D$ & $95 \%$ CI & Mdn & $\alpha$ \\
\hline VPVQ & 3.01 & 2.78 & {$[2.77,3.25]$} & 3.00 & .82 \\
EVQ & 2.20 & 0.68 & {$[2.14,2.25]$} & 2.18 & .94 \\
\hline
\end{tabular}

Note. VPVQ = Violence Propensity Vignette Questionnaire; EVQ = Evaluation of Violence Questionnaire; $\mathrm{M}=$ Mean; SD = Standard Deviation; $\mathrm{CI}=$ Confidence Interval; Mdn = Median; $\alpha=$ Cronbach's Alpha.

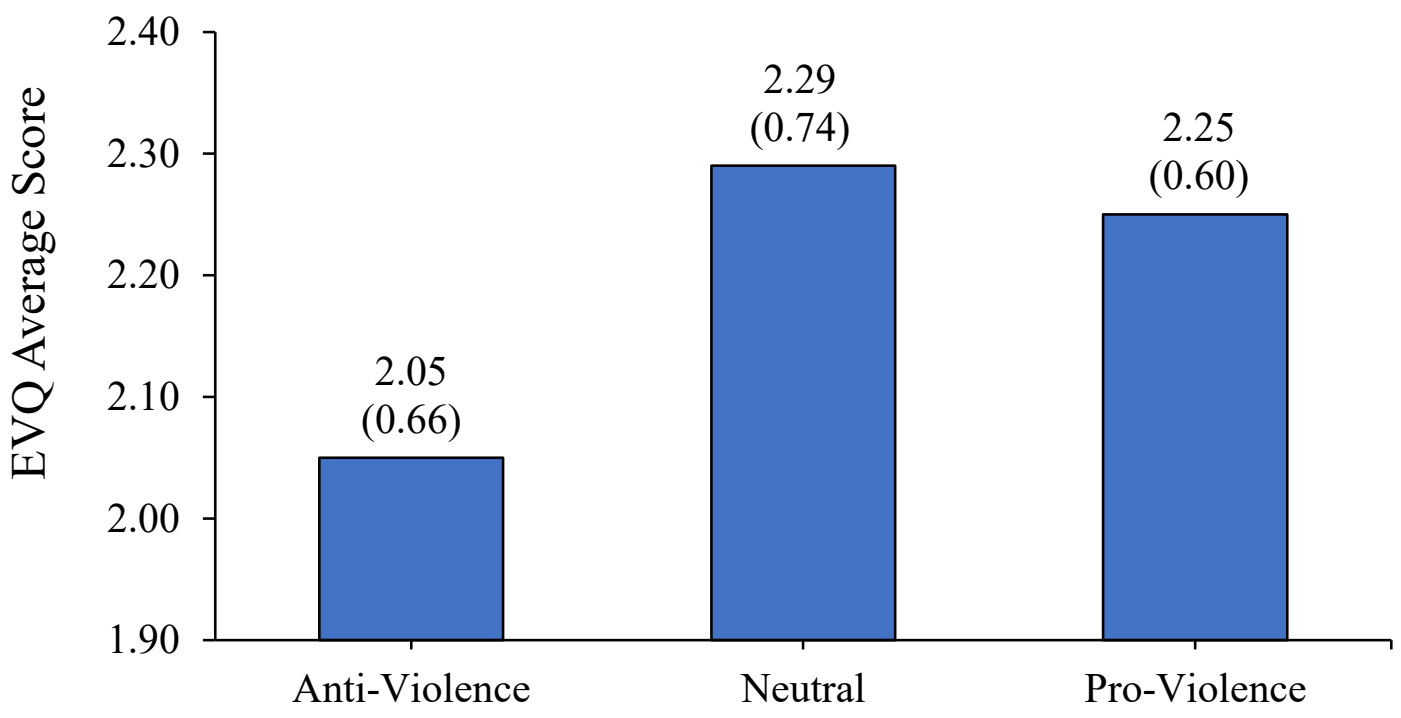

Condition

Figure 2. Evaluation of Violence (EVQ) scores by condition. 
To elucidate on this finding, responses to the experimental demand question were assessed. The pattern of results suggested that each response was differentially endorsed across the three conditions (see Table 3), and this was further supported by a significant chi-square test of independence, $\chi^{2}(4)=25.06, p<.001$. Specifically, a small proportion of those in the pro-violence condition believed the condition had a genuine effect, whereas the majority reported that the condition had no effect and nearly matched the number of participants who reported no effect in the neutral condition. Furthermore, the pro-violence condition contained the largest number of non-genuine responses relative to the other two conditions. In contrast, a larger proportion of those in the anti-violence condition stated that the message had a genuine effect relative to those in the pro-violence and neutral conditions, though the majority still report that the condition had no effect. A similar pattern emerged when I examined the number of participants who provided an incorrect answer to one of the manipulation check questions but were not screened out. A larger number of participants provided an incorrect answer in the pro-violence condition $(n=33)$ than in the anti-violence $(n=18)$ or neutral $(n=6)$ conditions, suggesting that those in the pro-violence condition may have attended to the message to a lesser degree than those in the latter two conditions. These results provide further support that the proviolence condition did not successfully induce more positive evaluations of violence. 
Table 3

Responses to the Experimental Demand Question Within Each Experimental Group $(n=526)$

\begin{tabular}{lccc}
\hline Response & $\begin{array}{c}\text { Anti-Violence } \\
\%(n)\end{array}$ & $\begin{array}{c}\text { Neutral } \\
\%(n)\end{array}$ & $\begin{array}{c}\text { Pro-Violence } \\
\%(n)\end{array}$ \\
\hline $\begin{array}{l}\text { The message changed how I } \\
\text { think about violence }\end{array}$ & $30.3(53)$ & $19.9(35)$ & $11.4(20)$ \\
$\begin{array}{l}\text { My responses changed, but my } \\
\text { thoughts about violence did not }\end{array}$ & $14.9(26)$ & $10.2(18)$ & $20.6(36)$ \\
$\begin{array}{l}\text { The message did not change } \\
\text { how I think about violence }\end{array}$ & $54.9(96)$ & $69.9(123)$ & $68.0(119)$ \\
\hline
\end{tabular}

\section{Analysis of VPVQ Responses}

Before analyzing the rates of violent responding across the three experimental conditions, the Lagrange multiplier test was employed to determine whether the data were overdispersed. The test suggested that the ancillary parameter was larger than zero, $\mathrm{Z}=12.15, p<.001$, indicating that a negative binomial model would provide a better fit for the data. This result was further supported by the AIC and BIC values, such that the model with an estimated ancillary parameter produced smaller values $(\mathrm{AIC}=2363.75$, $\mathrm{BIC}=2380.81)$ than the standard Poisson model (i.e., the ancillary parameter fixed at zero; $\mathrm{AIC}=2732.65, \mathrm{BIC}=2745.44)$. Therefore, the subsequent analyses were conducted with negative binomial models containing an estimated ancillary parameter.

The first set of comparisons were dummy coded so that the neutral condition was designated as the control group (anti-violence $=1$ and 0, pro-violence $=0$ and 1 , neutral $=$ 0 and 0 ), and then recoded to produce the last comparison whereby the pro-violence condition was designated as the control group (anti-violence $=1$ and 0 , neutral group $=0$ and 1 , pro-violence group $=0$ and 0 ). Therefore, the model contained a single covariate 
(i.e., experimental condition) with the number of VPVQ violent responses as the outcome variable. Descriptive statistics are displayed in Table 4. The final model containing the dummy coded experimental conditions significantly improved upon the constant-only model, $\chi^{2}(2)=9.72, p=.008$. The anti-violence condition was significant, $B=-0.29, S E$ $=0.11, p=.01, \operatorname{Exp}(\mathrm{B})=0.75$, indicating that those in the anti-violence condition selected only 0.75 times as many violent responses as those in the neutral condition $(d=-$ $0.29,95 \%$ CI $[-0.50,-0.08])$. Similar results were obtained when the anti-violence group was compared to the pro-violence group, $B=-0.34, S E=0.11, p=.003, \operatorname{Exp}(\mathrm{B})=0.72$, indicating that those in the anti-violence condition selected only 0.72 times as many violence responses as those in the pro-violence condition $(d=-0.36,95 \%$ CI [-0.57, 0.15]). The pro-violence condition produced positive coefficients, but was nonsignificant, $B=.047, S E=0.11, p=.67, \operatorname{Exp}(\mathrm{B})=1.05$, indicating that those in the proviolence condition did not select a significantly different number of violent responses relative to those in the neutral condition $(d=0.06,95 \%$ CI $[-0.15,0.26])$. Therefore, those in the anti-violence condition selected fewer violent responses relative to those in the neutral condition and pro-violence conditions, whereas those in the pro-violence condition did not select a significantly different number of violent responses relative to those in the neutral condition.

Table 4

Descriptive Statistics for the VPVQ by Condition

\begin{tabular}{lccccc}
\hline & $M$ & $S D$ & $95 \%$ CI & Mdn & Range \\
\hline Anti-Violence & 2.41 & 2.66 & {$[2.02,2.81]$} & 2.00 & $0-10$ \\
Neutral & 3.23 & 2.92 & {$[2.79,3.66]$} & 3.00 & $0-10$ \\
Pro-Violence & 3.38 & 2.66 & {$[2.99,3.78]$} & 3.00 & $0-10$ \\
\hline
\end{tabular}


Note. VPVQ = Violence Propensity Vignette Questionnaire; $\mathrm{M}=$ Mean; SD = Standard Deviation; CI = Confidence Interval; Mdn = Median.

\section{Sensitivity Analysis}

Responses to the experimental demand question indicated that some participants may have responded in an exaggerated manner (i.e., "The message changed how I answered, but it didn't change how I really think about violence"). Therefore, participants from the anti-violence $(n=26)$ and pro-violence $(n=36)$ conditions who selected this option were excluded from the analysis to determine whether these responses influenced the results. All participants from the neutral condition were included because the question did not adequately address experimental demand for this condition (i.e., the Grand Canyon message was not designed to change evaluations of violence, but could have had an unintended effect). Descriptive information can be found in Table 5. The pattern of results were the same: violent responses were lower for the anti-violence condition relative to the neutral condition, $B=-0.34, S E=.12, p=.006, \operatorname{Exp}(\mathrm{B})=0.72$, and proviolence condition, $B=-0.36, S E=.13, p=.005, \operatorname{Exp}(\mathrm{B})=0.70$, whereas the number of violent responses selected in the pro-violence condition were not significantly different from the number selected in the neutral condition, $B=0.02, S E=.12, p=.86, \operatorname{Exp}(\mathrm{B})=$ 1.02. Therefore, there is evidence that the effects obtained in the original analysis were not due to exaggerated or non-genuine responding. Two further analyses were conducted that replicate the analyses reported here, but also excluded participants who indicated they were not attracted to women. The pattern of results remained the same, albeit with slightly smaller effects. The results of these two analyses and a full comparison of the descriptive statistics across each analysis can be found in Appendices K, L, and M. 


\section{VPVQ as a Dichotomous Outcome}

After dichotomously coding the VPVQ, separate phi coefficients were calculated for each combination of the experimental condition. Non-violent responses were coded as zeros and one or more violent response were coded as ones. The anti-violence condition was coded as a one and the neutral condition was coded as a zero. The overall rate of violent responding was high, with $72.1 \%(n=379)$ choosing at least one violent response (see Table 6). Significant negative associations were obtained between the neutral and anti-violence condition, $\varphi=-.15, p=.004$, and the pro-violence and anti-violence condition, $\varphi=-.22, p<.001$, whereas a non-significant association was obtained for the neutral and pro-violence condition, $\varphi=.07, p=.21$. Therefore, in accordance with the previous analyses, those in the anti-violence condition selected violent responses to a smaller degree than those in the other two conditions.

Table 5

Sensitivity Analysis Descriptive Statistics for the VPVQ by Condition

\begin{tabular}{lccccc}
\hline & $M$ & $S D$ & $95 \%$ CI & Mdn & Range \\
\hline Anti-Violence & 2.31 & 2.62 & {$[1.88,2.73]$} & 2.00 & $0-10$ \\
Neutral & 3.23 & 2.92 & {$[2.79,3.66]$} & 3.00 & $0-10$ \\
Pro-Violence & 3.30 & 2.60 & {$[2.86,3.73]$} & 3.00 & $0-10$ \\
\hline
\end{tabular}

Note. VPVQ = Violence Propensity Vignette Questionnaire; $\mathrm{M}=$ Mean; SD = Standard Deviation; CI = Confidence Interval; $\mathrm{Mdn}=$ Median.

Table 6

Violent and Non-Violent Responses Across the Experimental Conditions $(n=526)$ Anti-Violence Neutral Pro-Violence

\begin{tabular}{lllc} 
Response & $\%(n)$ & $\%(n)$ & $\%(n)$ \\
\hline One or More Violent Responses & $60.6(106)$ & $75.0(132)$ & $80.6(141)$ \\
No Violent Responses & $39.4(69)$ & $25.0(44)$ & $19.4(34)$
\end{tabular}




\section{Discussion}

The primary aim of this study was to determine whether manipulating evaluative attitudes towards violence would influence violent responding on an analogue measure of violent behaviour. Consistent with hypotheses, the anti-violence message made evaluations of violence more negative and resulted in fewer violent responses on the VPVQ. The corresponding effect sizes were small (see Cohen, 1992) and equated to less than a full vignette fewer violent responses on the VPVQ relative to those in the neutral condition. The results are consistent with prior research that utilized the anti-violence manipulation, though the magnitude of the effect was slightly larger for the EVQ $(d=-$ 0.33 vs -0.24 ; see Nunes et al., 2019a) and the VPVQ $(d=-0.29$ vs -0.23 ; see Nunes et al., 2019a). In contrast, the pro-violence condition did not make evaluations of violence significantly more positive or result in significantly more violent responding relative to those in the neutral condition. In fact, evaluations of violence trended towards being more negative than evaluations reported by those in the neutral condition, though there was a trend towards more violent responding on the VPVQ. Similar results were obtained when the VPVQ was coded as a dichotomous outcome: participants assigned to the antiviolence condition responded non-violently to a larger degree than those in the neutral and pro-violence conditions.

The pattern of results also corresponded with responses to the experimental demand question such that few participants believed the pro-violence message had an effect whereas a noticeably larger proportion believed that the anti-violence condition genuinely changed evaluations of violence. That being said, the majority of participants reported that the manipulations did not have an effect on evaluations of violence 
regardless of what condition they were assigned to. It is worth acknowledging that this question was included as a rough measure of experimental demand and was best utilized as a way of identifying those who provided non-genuine responses to the VPVQ rather than a way of determining whether the experimental conditions were effective. Supplementary analyses comparing those who believed the experimental condition had a genuine effect and those who believed the experimental did not have a genuine effect within each experimental condition (i.e., pro-violence and anti-violence) revealed no significant differences in responding to the VPVQ, suggesting that the anti-violence message may have been more effective than what was indicated by responses to the experimental demand question.

In an attempt to reduce possible noise attributed to non-genuine responding or a lack of correspondence between participant characteristics and the measures, analyses were re-run while excluding participants who were not attracted to women and participants who provided non-genuine responses. The pattern of results remained the same, and were nearly identical to the original analysis when these two sub-groups were simultaneously excluded (see Appendix M). This reduces the possibility that the observed effects were due to experimental demand (e.g., responding based on guesses about the purpose of the study) or discordance between the situations presented in the VPVQ and the sexual preferences of the sample.

Altogether, the results suggest a causal relationship between negative evaluations of violence and reduced violent responding, but are inconclusive regarding the role of positive evaluations of violence. The ineffectiveness of the pro-violence condition leads to some ambiguity about whether the manipulation was faulty or whether there are 
limitation's regarding the malleability of evaluative attitudes toward violence. As such, it seems unfit to interpret the results solely as a complete test of the causal relationship between evaluations and violent behaviour. The results will therefore be interpreted with both of these considerations in mind.

\section{Limited Malleability}

The relative success of the anti-violence condition over the pro-violence condition could be attributed to a general negativity bias, whereby negative inputs, objects, or stimuli are weighted as more important than positive stimuli (see Baumeister, Bratslavky, Finkenauer, \& Vohs, 2001; Rozin \& Roysman, 2001). Negativity biases have been documented across a wide range of psychological phenomena (see Baumeister al., 2001), with some of the strongest evidence arising from impression formation research. Evidence from this literature suggests that negative information outweighs the impact of positive information when forming impressions of other people, such that negative information can have a drastic impact on impressions that are not equaled or offset by positive information (Fiske, 1980; Rydell \& McConnell, 2006; Skowronski \& Carlston, 1989; see Baumeister et al., 2001). Similarly, there is evidence for a negativity bias in attitude formation. For example, Fazio, Eiser, and Shook (2004) created a computer game where participants were exposed to novel stimuli (i.e., a large array of differently shaped and speckled beans) that led to either positive or negative outcomes (i.e., either good to eat or harmful to eat). Participants quickly learned to avoid the beans that led to negative outcomes during the learning phase and evaluated these beans as being negative. A generalization trial then presented a series of beans that blended the characteristics of the good and bad beans. The equally blended beans were more likely to be evaluated 
negatively than positively, demonstrating a negativity bias for the balanced stimuli. A series of follow-up studies demonstrated that the negativity bias could be eliminated during the learning phase by promoting approach behaviour, but the negativity bias always persisted during the generalization phase. Therefore, there is evidence that stimuli carrying negative connotations or stimuli that are directly linked to negative experiences may have a stronger cognitive and subsequent behavioural impact than equally positive stimuli. Given that the anti-violence message was comprised of a series of negative outcomes, it is possible that these arguments were inherently more potent and resonated with real consequences to a larger degree than the pro-violence message.

In addition to being less potent, many people likely believe that reckless acts of violence are inherently bad and could make positive attitudinal change more difficult to achieve. Research regarding morally bounded attitudes and beliefs supports this proposition. For example, Goodwin, and Darley (2012) explored the perceived objectivity of positively and negatively valanced moral actions (e.g., stealing vs donating money). Beliefs about the wrongness of moral transgressions were rated as more objective than beliefs about positively valanced moral behaviours and were associated with more discomfort with disagreeing others. Moral attitudes have also been found to have an extra element of strength that is not present in non-moral attitudes. For example, Skitka, Bauman, and Sargis (2005) found that moral convictions accounted for significant variance over and above other elements of attitudinal strength (e.g., importance, extremity, etc.) when examining the interpersonal outcomes of diverging moral attitudes. Furthermore, some evidence suggests that providing convincing reasons may not have a large impact on moral decision-making. Stanley, Dougherty, Yang, Henne, and De 
Brigard (2018) exposed participants to classic and modern moral dilemmas and asked participants to make a dichotomous decision about how they would respond. Participants were then randomly assigned to read a series of reasons that opposed, supported, or both opposed and supported the participants initial decision. The results indicated that the reasons rarely altered initial decisions and that participants generally became more confident in their initial decision regardless of the reasons they read. In addition, the researchers found that reasons supporting the initial decision were evaluated more favorably than reasons that opposed their initial decision, suggesting that participants processed the information in a biased manner. Similar results were obtained in a later study that replaced moral dilemmas with contentious socio-political issues (Stanley, Henne, Yang, \& De Brigard, 2019).

Therefore, insofar as the pro-violence condition was construed as a moral issue, evaluations towards violence could have been less malleable in the positive direction and more malleable in the negative direction. One obvious issue with this interpretation is that the base rate of violent responding was high, suggesting that most participants were not fundamentally opposed to violent responding. Although this is problematic, the high base rate does not preclude the possibility that many participants engaged with pro-violence condition from a morally bounded perspective (i.e., violence is generally wrong and bad) that minimized the manipulations overall effectiveness. Furthermore, Skitka et al. (2005) suggests that moral convictions are idiosyncratic and can be selectively applied in an inconsistent, and perhaps hypocritical, manner. As an example, the authors cite evidence that taking a pro-life stance towards abortion does not necessarily generalize to other prolife issues such as capital punishment (e.g., Lester, 2000; Sawyer, 1982; see also Wiecko 
\& Gau, 2008). Given that the VPVQ contains some extremely provoking situations, a similar process may be occurring. Many of the vignettes could be perceived as moral transgressions (e.g., a person stealing your money or trying to pickup your girlfriend or wife) that could induce a higher rate of violent responding among typically non-violent men. More work needs to be done to substantiate these possibilities and explore other factors that could limit the malleability of evaluative attitudes towards violence (e.g., personally endorsed values; see Seddig \& Davidov, 2018).

\section{Ineffective Message}

Research has established that convincing messages generally require strong arguments to induce attitude change (e.g., Carpenter, 2015; Mackie, Worth, \& Asuncion, 1990; Park et al., 2007; Petty \& Cacioppo, 1979, 1984) and that counter attitudinal messages increase the rate at which message recipients engage in counterarguing (e.g., Ditto \& Lopez, 1990; Eagly, Kulesa, Brannon, Shaw, \& Hutson-Comeaux, 2000). This raises the possibility that the anti-violence message contained strong arguments that were genuinely persuasive, whereas the pro-violence message contained weak arguments that were ineffective and promoted counterarguing. Furthermore, it is possible that the proviolence message led to hostile reactions from participants. Some research suggests that convincing messages can produce anger and negative thoughts when they are perceived as insulting, weak, or as restricting freedom (see Kim, Levine, \& Allen, 2013, 2017). These reactions can then produce resistance to the message or even produce the opposite effect, where attitudes become stronger in the undesired direction. Both of these outcomes have been observed in regards to anti-sexual aggression interventions (see Malamuth, Huppin, \& Linz, 2018) and anti-violence interventions (see Cárdaba, Briñol, 
Brändle, \& Ruiz-SanRomán, 2016). One notable caveat is that these interventions were primarily ineffective for those who were at a higher risk of sexual aggression (Malamuth et al., 2018) or those who had higher levels of trait aggression (Cárdaba et al., 2016). Therefore, the opposite could have occurred in the current study where those with lower trait aggression perceived the pro-violence message to be absurd or insulting, resulting in hostility and resistance to the message.

Alternatively, it is possible that the pro-violence condition contained strong arguments that only affected evaluations of self-defence (or some similar protective role) rather than violence more broadly. The self-defence scenario was selected to provide a reasonable and justifiable foundation for making pro-violence arguments, but this may have unintentionally reduced the generalizability of the manipulation. There was a high rate of violent responding to the vignettes that alluded to a male protective role (e.g., a man trying to pickup your girlfriend or wife), suggesting that violence was considered justifiable in these circumstances. If this was the case, it is unlikely that strengthening an already strong proclivity to respond violently to "justifiable" situations would extend to scenarios where violence is not as easily justified. Further work regarding the justifiability of violence for each of the VPVQ scenarios could help to clarify this possibility and guide future manipulations.

\section{Practical Implications}

The current study contributes to the existing literature by successfully replicating Nunes et al. (2019a), thus providing further evidence that reducing evaluations of violence decreases violent responding. Generally, these two studies suggest that evaluations of violence decrease when the negative aspects of violent behaviour are made 
salient, and this subsequently decreases the number of violent acts that one is willing to engage in. Conversely, it appears that the pro-violence condition had no effect, but this could be attributed to the nature of evaluative attitudes or to the failings of the manipulation. Given that both of these studies were conducted with community men, it cannot be assumed that this pattern of findings would generalize to other populations (e.g., incarcerated men), making the practical implications of these findings difficult to draw.

It is clear that more research is necessary to determine the best approach for inducing positive evaluations of violence among community men. If future efforts are equally unsuccessful, then it is possible that evaluations of violence are indeed less malleable in the positive direction and more malleable in the negative direction. This outcome would not suggest that evaluations of violence are irrelevant to violent responding, but rather open the possibility that there are structural and functional differences in evaluative attitudes for those who display a higher propensity for violence. This hypothesis could be tested by identifying whether incarcerated men or men with higher levels of trait aggression display different patterns of responding to the same antiviolence and pro-violence conditions. If men from these populations show more violent responding to the pro-violence condition, this would indicate more malleability in the positive direction relative to men from the community. Subsequent research could then discern the reasons for this disparity, providing an opportunity to explore structural and functional differences in evaluative attitudes that could inform targets for therapy. 


\section{Strengths and Limitations}

The present study contained a number of strengths. For example, the overall experimental design and inclusion of a neutral group improved upon many pro-criminal attitude treatment studies that neglected to include control groups (See Banse et al., 2013) and could not make causal inferences about the variables under investigation. Furthermore, the inclusion of an experimental demand question allowed for sensitivity analyses to be conducted while excluding those who provided exaggerated responses, and the attention and manipulation check questions allowed us to screen out those who did not take the study seriously. Finally, sampling men primarily between the ages of 18 and 40 improved the confidence with which the results could be generalized to this subgroup of men.

Despite the noted strengths, the current study also contained a number of limitations. First, the desired sample size of 300 participants (or more) per condition was not obtained. This number was derived from a power analysis conducted using the effect sizes obtained in Nunes et al. (2019a), but limited time and resources made this sample size unattainable. Therefore, it is possible that the pattern of results can be attributed to low power, but it appears that the pro-violence condition would have produced a noticeably smaller effect size regardless of the sample size. Second, the order of presentation and between-participants design of the study limited interpretations of the degree of attitude change. The EVQ was always completed last, leaving the possibility that evaluations of violence were influenced by the VPVQ in unexpected ways. This limitation could be addressed in future studies by counterbalancing the presentation of the two measures. Furthermore, recent literature indicates that within-participant 
measurements are important when assessing the dynamic nature of risk factors (Banse et al., 2013; Kroner \& Yessine, 2013), suggesting that adopting a pre-post attitude measurement design would conceptually parallel the methods and processes used in the treatment literature. This is an important consideration given that recent research has failed to find significant associations between within-person changes in pro-criminal attitudes and reduced recidivism (see Banse et al., 2013; Howard \& Doorn, 2018). Lastly, the absence of possible moderating variables decreased the interpretability of the results. Reasons why the pro-violence condition was ineffective could have been explored using moderation analyses (e.g., high vs low trait aggression), and provided a clearer indication of what needs to be addressed in subsequent projects (e.g., resistance to the pro-violence message).

\section{Future Research}

As previously mentioned, future research should test whether changes in evaluative attitudes are moderated by trait aggression and other relevant variables. This will contribute to our understanding of how various messages are processed by those with differing propensities for aggressive behaviour. If it appears that evaluative attitudes are less malleable in the positive direction among those lower in trait aggression (or community men in general), it may be fruitful to discern whether moral convictions or a general negativity bias can account for these differences. Some research suggests that attitude objects can be construed in multiple ways (e.g., evaluated in moral vs practical terms; see Van Bavel, Packer, Haas, \& Cunningham, 2012) and may provide a potential mechanism that determines the malleability of evaluative attitudes. In addition to this conceptual work, further research can explore the effectiveness of similar interventions 
among violent offenders. This could be accomplished with a randomized clinical trial containing a control condition and an intervention that integrates the realistically negative consequences of violent behaviour to target evaluative attitudes towards violence. The effectiveness of this intervention could be gauged through repeated assessments of evaluations towards violence, an analogue measure of violent behaviour (e.g., the VPVQ), and rates of recidivism.

Investigations into the stability of attitudinal changes will also be a valuable endeavor. A recent study found that self-reported pro-criminal attitudes increased when comparing measures taken at the end of one treatment program and the beginning of a second treatment program (see Juarez \& Howard, 2018), suggesting that the effects of these interventions could be transitory. The stability of attitude changes could have important implications for what is targeted in therapy and how these changes are achieved. Furthermore, it would be interesting to test whether the anti-violence message is effective after a delay (e.g., 24 hours or a week). The arguments highlight the realistic negative outcomes of acting violently and may be more effective than other messages that question the reader's character or social competence (these latter strategies have been used in other studies, but likely create resistance to the convincing message; see Cárdaba et al., 2016 for an example).

Lastly, research addressing the justifiability of violent responses to the various situations presented in the VPVQ may provide important information. Understanding which vignettes are considered justifiable by the largest number of men could dictate what needs to be targeted in general anti-violence campaigns and also inform future proviolence manipulations. A large proportion of males might concurrently believe that 
violence is inherently bad but also justifiable under particular circumstances (e.g., man trying to pick up your girlfriend or wife), suggesting that gender role expectations could contribute to violent responding in these situations (see Bozkurt, Tartanoglu, \& Dawes, 2015; Hong, 2000).

\section{Conclusion}

The present study elaborated on the possible causal relationship between evaluations of violence and violent behaviour. The results provided further evidence that less negative evaluations of violence may be causally related to reduced violent behaviour, but further research is needed to establish the role of positive evaluations of violence. Future projects should focus on improving the pro-violence condition and establishing which mechanisms can account for the observed results. If evaluations of violence appear to be less malleable in the positive direction, morally bounded attitudes and a propensity to give more weight to negative stimuli may be able to account for this lack of flexibility. The implications of such findings will advance our understanding of violent behaviour and possibly improve approaches to therapy. 


\section{References}

Ajzen, I. (1991). The Theory of Planned Behavior. Organizational Behavior and Human Decision Processes, 50, 179-211. doi: 10.1016/0749-5978(91)90020-T

Ajzen, I. (2001). Nature and operation of attitudes. Annual Review of Psychology, 52, 2758. doi: 10.1146/annurev.psych.52.1.27

Ajzen, I., \& Fishbein, M. (2005). The influence of attitudes on behavior. In D. Albarracín, B. T. Johnson \& M. P. Zanna (Eds.), The handbook of attitudes; the handbook of attitudes (pp. 173-221) Lawrence Erlbaum Associates Publishers, Mahwah, NJ.

Allport, G. W. (1935). Attitudes. In C. Murchison (Ed.), Handbook of social psychology (pp. 798-884). Worcester, MA: Clark University Press.

Anderson, C. A., \& Bushman, B. J. (2002). Human aggression. Annual Review of Psychology, 53(1), 27-51. doi: 10.1146/annurev.psych.53.100901.

Andrews, D. A., Bonta, J., \& Hoge, R. D. (1990). Classification for effective rehabilitation: Rediscovering psychology. Criminal Justice and Behavior, 17(1), 19-52. doi: $10.1177 / 0093854890017001004$

Archer, J. (2004). Which attitudinal measures predict trait aggression? Personality and Individual Differences, 36(1), 47-60. doi: 10.1016/S0191-8869(03)00050-3

Bandura, A. (1973). Aggression: A social learning analysis. Englewood Cliffs, N.J: Prentice-Hall.

Banse, R., Koppehele-Gossel, J., Kistemaker, L. M., Werner, V. A., \& Schmidt, A. F. (2013). Pro-criminal attitudes, intervention, and recidivism. Aggression and Violent Behavior, 18(6), 673-685. doi: 10.1016/j.avb.2013.07.024 
Baumeister, R. F., Bratslavsky, E., Finkenauer, C., \& Vohs, K. D. (2001). Bad is stronger than good. Review of General Psychology, 5(4), 323-370. doi: 10.1037/10892680.5.4.323

Bluemke, M. \& Zumbach, J. (2012). Assessing aggressiveness via reaction times online. Cyberpsychology: Journal of Psychosocial Research on Cyberspace, 6(1), article 5. doi: 10.5817/CP2012-1-5

Blumenthal, S., Gray, N. S., Shuker, R., Wood, H., Fonagy, P., Allonby, M., . . . Snowden, R. J. (2019). Implicit measurement of violence-related cognitions. Psychology of Violence, 9(2), 235-243. doi: 10.1037/vio0000194

Bonta, J., \& Andrews D. A. (2017). The psychology of criminal conduct (6 $6^{\text {th }}$ ed.). New York, NY: Routledge

Bozkurt, V., Tartanoglu, S., \& Dawes, G. (2015). Masculinity and violence: Sex roles and violence endorsement among university students. Procedia-Social and Behavioral Sciences, 205, 254-260.

Bumby, K. M. (1996). Assessing the cognitive distortions of child molesters and rapists: Development and validation of the MOLEST and RAPE scales. Sexual Abuse: Journal of Research and Treatment, 8(1), 37-54. doi: 10.1007/BF02258015

Cárdaba, M. A. M., Briñol, P., Brändle, G., \& Ruiz-SanRomán, J. A. (2016). The moderating role of aggressiveness in response to campaigns and interventions promoting anti-violence attitudes. Aggressive Behavior, 42(5), 471-482. doi: $10.1002 / \mathrm{ab} .21643$ 
Carpenter, C. J. (2015). A meta-analysis of the ELM's argument quality $\times$ processing type predictions. Human Communication Research, 41(4), 501-534. doi: $10.1111 /$ hcre. 12054

Coccaro, E. F., Fanning, J., \& Lee, R. (2017). Development of a social emotional information processing assessment for adults (SEIP-Q). Aggressive Behavior, 43(1), 47-59. doi: 10.1002/ab.21661

Cohen, J. (1992). A power primer. Psychological Bulletin, 112(1), 155-159. doi: $10.1037 / 0033-2909.112 .1 .155$

Conrey, F. R., \& Smith, E. R. (2007). Attitude representation: Attitudes as patterns in a distributed, connectionist representational system. Social Cognition, 25(5), 718735. doi: $10.1521 /$ soco.2007.25.5.718

Cooke, R., Dahdah, M., Norman, P., \& French, D. P. (2016). How well does the Theory of Planned Behaviour predict alcohol consumption? A systematic review and meta-analysis. Health Psychology Review, 10(2), 148-167. doi: $10.1080 / 17437199.2014 .947547$

Coxe, S., West, S. G., \& Aiken, L. S. (2009). The analysis of count data: A gentle introduction to Poisson regression and its alternatives. Journal of Personality Assessment, 91(2), 121-136. doi: 10.1080/00223890802634175

DeWall, C. N., Anderson, C. A., \& Bushman, B. J. (2011). The general aggression model: Theoretical extensions to violence. Psychology of Violence, 1(3), 245-258. doi: $10.1037 / \mathrm{a} 0023842$ 
Ditto, P. H., \& Lopez, D. F. (1992). Motivated skepticism: Use of differential decision criteria for preferred and nonpreferred conclusions. Journal of Personality and Social Psychology, 63(4), 568-584. doi: 10.1037/0022-3514.63.4.568

Douglas, K. S., \& Skeem, J. L. (2005). Violence risk assessment: Getting specific about being dynamic. Psychology, Public Policy, and Law, 11(3), 347-383. doi: $10.1037 / 1076-8971.11 .3 .347$

Eagly, A. H., \& Chaiken, S. (1993). The psychology of attitudes. Fort Worth, TX: Harcourt, Brace, Jovanovich.

Eagly, A. H., \& Chaiken, S. (2007). The advantages of an inclusive definition of attitude. Social Cognition, 25, 582-602. doi : 10.1521/soco.2007.25.5.582

Eagly, A. H., Kulesa, P., Brannon, L. A., Shaw, K., \& Hutson-Comeaux, S. (2000). Why counterattitudinal messages are as memorable as proattitudinal messages: The importance of active defense against attack. Personality and Social Psychology Bulletin, 26(11), 1392-1408. doi: 10.1177/0146167200263007

Fabrigar, L. R., MacDonald, T. K., Wegener, D. T. (2005). The structure of attitudes. In D. Albarracin, B. T. Johnson \& M. Zanna (Eds.), The handbook of attitudes (pp. 79-124). Mahwah, NJ: Lawrence Erlbaum

Fazio, R. H. (1990). Multiple processes by which attitudes guide behavior: The MODE model as an integrative framework. In M. P. Zanna (Ed.), Advances in experimental social psychology (Vol. 23, pp. 75-109). New York, NY: Academic Press.

Fazio, R. H. (2007). Attitudes as object-evaluation associations of varying strength. Social Cognition, 25, 664-703. doi: 10.1521/soco.2007.25.5.603 
Fazio, R. H., Eiser, J. R., \& Shook, N. J. (2004). Attitude formation through exploration: Valence asymmetries. Journal of Personality and Social Psychology, 87(3), 293311. doi: 10.1037/0022-3514.87.3.293

Fishbein, M., \& Ajzen, I. (1975). Belief, Attitude, Intention, and Behavior: An Introduction to Theory and Research. Reading, MA: Addison-Wesley.

Fiske, S. T. (1980). Attention and weight in person perception: The impact of negative and extreme behavior. Journal of Personality and Social Psychology, 38(6), 889906. doi: 10.1037/0022-3514.38.6.889

Gawronski, B., \& Bodenhausen, G. V. (2006). Associative and propositional processes in evaluation: An integrative review of implicit and explicit attitude change. Psychological Bulletin, 132(5), 692-731. doi: 10.1037/00332909.132.5.692

Gawronski, B., \& Bodenhausen, G. V. (2007). Unraveling the processes underlying evaluation: Attitudes from the perspective of the APE model. Social Cognition, 25(5), 687-717. doi: 10.1521/soco.2007.25.5.687

Gawronski, B., \& Bodenhausen, G. V. (2011). The Associative-Propositional Evaluation model: Theory, evidence, and open questions. In J. M. Olson, \& M. P. Zanna (Eds.), Advances in experimental social psychology, vol 44; advances in experimental social psychology, vol 44 (pp. 59-127) Academic Press, San Diego, CA.

Gilbert, F., Daffern, M., Talevski, D., \& Ogloff, J. R. P. (2013). The role of aggressionrelated cognition in the aggressive behavior of offenders: A General Aggression 
Model perspective. Criminal Justice and Behavior, 40(2), 119-138. doi: $10.1177 / 0093854812467943$

Glasman, L. R., \& Albarracín, D. (2006). Forming attitudes that predict future behavior: A meta-analysis of the attitude-behavior relation. Psychological Bulletin, 132, 778-822. doi: 10.1037/0033-2909.132.5.778

Goodwin, G. P., \& Darley, J. M. (2012). Why are some moral beliefs perceived to be more objective than others? Journal of Experimental Social Psychology, 48(1), 250-256. doi: 10.1016/j.jesp.2011.08.006

Greenwald, A. G., McGhee, D. E., \& Schwartz, J. L. K. (1998). Measuring individual differences in implicit cognition: The implicit association test. Journal of Personality and Social Psychology, 74(6), 1464-1480. doi: 10.1037/00223514.74.6.1464

Helmond, P., Overbeek, G., Brugman, D., \& Gibbs, J. C. (2015). A meta-analysis on cognitive distortions and externalizing problem behavior: Associations, moderators, and treatment effectiveness. Criminal Justice and Behavior, 42(3), 245-262. doi: 10.1177/0093854814552842

Hermann, C. A., \& Nunes, K. L. (2018). Implicit and explicit evaluations of sexual aggression predict subsequent sexually aggressive behavior in a sample of community men. Sexual Abuse, 30(5), 510-532. doi: 10.1177/1079063216682952

Hermann, C. A., Nunes, K. L., \& Maimone, S. (2018). Examining implicit and explicit evaluations of sexual aggression and sexually aggressive behavior in men recruited online. Sexual Abuse, 30(5), 484-509. doi: 10.1177/1079063216681560 
Hoddenbagh, J., McDonald, S. E., \& Zhang, T. (2014). An estimation of the economic impact of violent victimization in Canada, 2009. Research and Statistics Division, Department of Justice Canada.

Hong, L. (2000). Toward a transformed approach to prevention: Breaking the link between masculinity and violence. Journal of American College Health, 48(6), 269-279.

Howard, M. V. A., \& van Doorn, G. (2018). Within-treatment change in antisocial attitudes and reoffending in a large sample of custodial and community offenders. Law and Human Behavior, 42(4), 321-335. doi: 10.1037/1hb0000290

Johnson, B. T. (1994). Effects of outcome-relevant involvement and prior information on persuasion. Journal of Experimental Social Psychology, 30(6), 556-579. doi: 10.1006/jesp.1994.1026

Juarez, T., \& Howard, M. V. A. (2018). Assessing offender change over treatment: The influence of treatment context on self-reported antisocial attitudes. Manuscript in preparation.

Kautonen, T., van Gelderen, M. W., \& Fink, M. (2015). Robustness of the Theory of Planned Behavior in predicting entrepreneurial intentions and actions. Entrepreneurship Theory and Practice, 39(3), 655-674. doi:10.1111/etap.12056

Kim, S., Levine, T. R., \& Allen, M. (2017). Comparing separate process and intertwined models for reactance. Communication Studies, 64(3), 273-295. doi: $10.1080 / 10510974.2012 .755639$ 
Kim, S., Levine, T. R., \& Allen, M. (2017). The intertwined model of reactance for resistance and persuasive boomerang. Communication Research, 44(7), 931-951. doi: $10.1177 / 0093650214548575$

Kraus, S. J. (1995). Attitudes and the prediction of behavior: A meta-analysis of the empirical literature. Personality and Social Psychology Bulletin, 21, 58-75. doi: $10.1177 / 0146167295211007$

Kroner, D. G., \& Yessine, A. K. (2013). Changing risk factors that impact recidivism: In search of mechanisms of change. Law and Human Behavior, 37(5), 321-336. doi: $10.1037 / \mathrm{lhb} 0000022$

Leippe, M. R., \& Elkin, R. A. (1987). When motives clash: Issue involvement and response involvement as determinants of persuasion. Journal of Personality and Social Psychology, 52(2), 269-278. doi: 10.1037/0022-3514.52.2.269

Lester, D. (2000). Is there a consistent pro-life attitude? Advances in Psychology, 1, 1-9. Mackie, D. M., Worth, L. T., \& Asuncion, A. G. (1990). Processing of persuasive ingroup messages. Journal of Personality and Social Psychology, 58(5), 812-822. doi: $10.1037 / 0022-3514.58 .5 .812$

Malamuth, N. M., Huppin, M., \& Linz, D. (2018). Sexual assault interventions may be doing more harm than good with high-risk males. Aggression and Violent Behavior, 41, 20-24. doi: 10.1016/j.avb.2018.05.010

Maruna, S., \& Copes, H. (2005). What have we learned from five decades of neutralization research? Crime and Justice, 32, 221-320. 
Maruna, S., \& Mann, R. E. (2006). A fundamental attribution error? Rethinking cognitive distortions. Legal and Criminological Psychology, 11(2), 155-177. doi: $10.1348 / 135532506 \times 114608$

Miller, W. B. (1958). Lower class culture as a generating milieu of gang delinquency. Journal of Social Issues, 14(3), 5-19. doi: 10.1111/j.1540-4560.1958.tb01413.x

Mills, J. F., \& Kroner, D. G. (2007). Measures of criminal attitudes and associatesRevised. Unpublished measure.

Mills, J. F., Kroner, D. G., \& Forth, A. E. (2002). Measures of Criminal Attitudes and Associations (MCAA): Development, factor structure, reliability, and validity. Assessment, 9(3), 240-253. doi: 10.1177/1073191102009003003

Mills, J. F., Kroner, D. G., \& Hemmati, T. (2004). The Measures of Criminal Attitudes and Associates (MCAA): The prediction of general and violent recidivism. Criminal Justice and Behavior, 31(6), 717-733. doi: 10.1177/0093854804268755

Nunes, K. L., Hermann, C. A., Maimone, S., Atlas, M., \& Grant, B. A. (2019). The Violence Propensity Vignette Questionnaire (VPVQ): A measure of violent behavior for research in forensic and non-forensic settings and populations. Manuscript submitted for publication.

Nunes, K. L., Hermann, C. A., Maimone, S., \& Woods, M. (2015). Thinking clearly about violent cognitions: Attitudes may be distinct from other cognitions. Journal of Interpersonal Violence, 30(8), 1322-1347. doi: 10.1177/0886260514540329

Nunes, K. L., Hermann, C. A., \& Ratcliffe, K. (2013). Implicit and explicit attitudes toward rape are associated with sexual aggression. Journal of Interpersonal Violence, 28(13), 2657-2675. doi: 10.1177/0886260513487995 
Nunes, K. L., Hermann, C. A., White, K., Pettersen, C., \& Bumby, K. (2018). Attitude may be everything, but is everything an attitude? Cognitive distortions may not be evaluations of rape. Sexual Abuse: Journal of Research and Treatment, 30(1), 4362. doi: $10.1177 / 1079063215625489$

Nunes, K. L., Pedneault, C. I., \& Hermann, C. A. (2019a). The effect of evaluative attitudes on violent behavior. Manuscript in preparation.

Nunes, K. L., Pedneault, C. I. \& Hermann, C. A. (2019b). Development and validation of the Evaluation of Violence Questionnaire. Manuscript in preparation

Nunes, K. L., Pedneault, C. I., Filleter, W. E., Maimone, S., Blank, C., \& Atlas, M. (2019). “I Know Correlation Doesn't Prove Causation, but...”: Are We Jumping to Unfounded Conclusions About the Causes of Sexual Offending? Sexual Abuse, 31(2), 220-236. doi: 10.1177/1079063217729156

Osgood, C. E. (1952). The nature and measurement of meaning. Psychological Bulletin, 49(3), 197-237. doi: 10.1037/h0055737

Park, H. S., Levine, T. R., Westerman, C. Y. K., Orfgen, T., \& Foregger, S. (2007). The effects of argument quality and involvement type on attitude formation and attitude change: A test of dual-process and social judgment predictions. Human Communication Research, 33(1), 81-102. doi: 10.1111/j.1468-2958.2007.00290.x

Petty, R. E., \& Briñol, P. (2014). The elaboration likelihood and meta-cognitive models of attitudes: Implications for prejudice, the self, and beyond. In J. W. Sherman, B. Gawronski, \& Y. Trope (Eds.), Dual-process theories of the social mind (pp. 172-187). New York, NY: Guilford. 
Petty, R. E., Briñol, P., \& DeMarree, K. G. (2007). The meta-cognitive model (MCM) of attitudes: Implications for attitude measurement, change, and strength. Social Cognition, 25(5), 657-686. doi: 10.1521/soco.2007.25.5.657

Petty, R. E., \& Cacioppo, J. T. (1979). Issue involvement can increase or decrease persuasion by enhancing message-relevant cognitive responses. Journal of Personality and Social Psychology, 37(10), 1915-1926. doi: 10.1037/00223514.37.10.1915

Petty, R. E., \& Cacioppo, J. T. (1984). The effects of involvement on responses to argument quantity and quality: Central and peripheral routes to persuasion. Journal of Personality and Social Psychology, 46(1), 69-81. doi: $10.1037 / 0022-3514.46 .1 .69$

Petty, R. E., Cacioppo, J. T., \& Goldman, R. (1981). Personal involvement as a determinant of argument-based persuasion. Journal of Personality and Social Psychology, 41(5), 847-855. doi: 10.1037/0022-3514.41.5.847

Polaschek, D. L. L., Bell, R. K., Calvert, S. W., \& Takarangi, M. K. T. (2010). Cognitivebehavioural rehabilitation of high-risk violent offenders: Investigating treatment change with explicit and implicit measures of cognition. Applied Cognitive Psychology, 24(3), 437-449. doi: 10.1002/acp.1688

Polaschek, D. L. L., Collie, R. M., \& Walkey, F. H. (2004). Criminal Attitudes to Violence: Development and preliminary validation of a scale for male prisoners. Aggressive Behavior, 30(6), 484-503. doi: 10.1002/ab.20081

Qualtrics (2014). Panel Book 2014. Provo, Utah: Qualtrics Labs, Inc. 
Rich, A., Brandes, K., Mullan, B., \& Hagger, M. S. (2015). Theory of Planned Behavior and adherence in chronic illness: A meta-analysis. Journal of Behavioral Medicine, 38(4), 673-688. doi:10.1007/s10865-015-9644-3

Rozin, P., \& Royzman, E. B. (2001). Negativity bias, negativity dominance, and contagion. Personality and Social Psychology Review, 5(4), 296-320. doi: 10.1207/S15327957PSPR0504_2

Rydell, R. J., \& McConnell, A. R. (2006). Understanding implicit and explicit attitude change: A systems of reasoning analysis. Journal of Personality and Social Psychology, 91(6), 995-1008. doi: 10.1037/0022-3514.91.6.995

Sawyer, D. O. (1982). Public attitudes toward life and death. Public Opinion Quarterly, 46(4), 521-533. doi: 10.1086/268749

Schwarz, N. (2007). Attitude construction: Evaluation in context. Social Cognition, 25(5), 638-656. doi: 10.1521/soco.2007.25.5.638

Seddig, D., \& Davidov, E. (2018). Values, attitudes toward interpersonal violence, and interpersonal violent behavior. Frontiers in Psychology, 9, 604. doi: 10.3389/fpsyg.2018.00604

Serin, R. C., Lloyd, C. D., Helmus, L., Derkzen, D. M., \& Luong, D. (2013). Does intraindividual change predict offender recidivism? Searching for the holy grail in assessing offender change. Aggression and Violent Behavior, 18(1), 32-53. doi: 10.1016/j.avb.2012.09.002

Shepherd, J. P., Qureshi, R., Preston, M. S., \& Levers, B. G. (1990). Psychological distress after assaults and accidents. BMJ: British Medical Journal, 301(6756), 849. 
Shepherd, J. P., Shapland, M., Pearce, N. X., \& Scully, C. (1990). Pattern, severity and aetiology of injuries in victims of assault. Journal of the Royal Society of Medicine, 83(2), 75-78. doi: 10.1177/014107689008300206

Skitka, L. J., Bauman, C. W., \& Sargis, E. G. (2005). Moral conviction: Another contributor to attitude strength or something more? Journal of Personality and Social Psychology, 88(6), 895-917. doi: 10.1037/0022-3514.88.6.895

Skowronski, J. J., \& Carlston, D. E. (1989). Negativity and extremity biases in impression formation: A review of explanations. Psychological Bulletin, 105(1), 131-142. doi: 10.1037/0033-2909.105.1.131

Snowden, R. J., Gray, N. S., Smith, J., Morris, M., \& MacCulloch, M. J. (2004). Implicit affective associations to violence in psychopathic murderers. Journal of Forensic Psychiatry \& Psychology, 15(4), 620-641. doi: 10.1080/14789940412331313377

Stanley, M. L., Dougherty, A. M., Yang, B. W., Henne, P., \& De Brigard, F. (2018). Reasons probably won't change your mind: The role of reasons in revising moral decisions. Journal of Experimental Psychology: General, 147(7), 962-987. doi: $10.1037 /$ xge0000368

Stanley, M. L., Henne, P., Yang, B. W., \& De Brigard, F. (2019). Resistance to position change, motivated reasoning, and polarization. Political Behavior, doi: 10.1007/s11109-019-09526-Z

Stewart, E. A., Schreck, C. J., \& Simons, R. L. (2006). “I ain’t gonna let no one disrespect me": Does the code of the street reduce or increase violent victimization among African American adolescents? Journal of Research in Crime and Delinquency, 43(4), 427-458. doi: 10.1177/0022427806292338 
Stolzenberg, L., \& D’Alessio, S. J. (2008). Co-offending and the age-crime curve. Journal of Research in Crime and Delinquency, 45(1), 65-86. doi: $10.1177 / 0022427807309441$

Strader, M. K., \& Katz, B. M. (1990). Effects of a persuasive communication on beliefs, attitudes, and career choice. The Journal of Social Psychology, 130(2), 141-150. doi: $10.1080 / 00224545.1990 .9924564$

Sykes, G. M., \& Matza, D. (1957). Techniques of neutralization: A theory of delinquency. American Sociological Review, 22, 664-670. doi: 10.2307/2089195

Taylor, H. F. (1971). Semantic differential factor scores as measures of attitude and perceived attitude. The Journal of Social Psychology, 83(2), 229-234. doi: $10.1080 / 00224545.1971 .9922467$

Van Bavel, J. J., Packer, D. J., Haas, I. J., \& Cunningham, W. A. (2012). The importance of moral construal: Moral versus non-moral construal elicits faster, more extreme, universal evaluations of the same actions. PloS one, 7(11).

Wakeling, H., Beech, A. R., \& Freemantle, N. (2013). Investigating treatment change and its relationship to recidivism in a sample of 3773 sex offenders in the UK. Psychology, Crime \& Law, 19(3), 233-252. doi: 10.1080/1068316X.2011.626413

Wiecko, F. M., \& Gau, J. M. (2008). Every life is sacred. . kind of: Uncovering the sources of seemingly contradictory public attitudes toward abortion and the death penalty. The Social Science Journal, 45(4), 546-564. doi:

10.1016/j.soscij.2008.09.007 
Wilkinson, J. (2005). Evaluating evidence for the effectiveness of the reasoning and rehabilitation programme. Howard Journal of Criminal Justice, 44(1), 70-85. doi: $10.1111 / j .1468-2311.2005 .00356 . x$

Wilson, T. D., Lindsey, S., \& Schooler, T. Y. (2000). A model of dual attitudes. Psychological Review, 107(1), 101-126. doi: 10.1037/0033-2 


\section{Appendix A}

\section{The Violence Propensity Vignette Questionnaire (VPVQ)}

\section{INSTRUCTIONS}

Please read the situations described below and say what you would really do if you were in that situation right now by choosing one of the response options.

\section{RESPONSE OPTIONS}

What do you do?

1. Report it to someone-Report what he's doing (or what he did) to someone like the manager, police, or security, and ask them to deal with the problem

2. Talk it out - Without insulting him, say something to let him know you're not okay with what he's doing (or what he did) and to try to work things out peacefully

3. Insult him - Say something insulting to him, like swearing at him or calling him a name

4. Joke about it - Joke about it to yourself or other people around you

5. Shove him

6. Hit, punch, kick, or tackle him

7. Threaten to hurt him

8. Ignore it - Don't do or say anything about it

9. Leave - Go somewhere else to get away from the person or situation 


\section{VIGNETTE 1 - OBNOXIOUS ROOMMATE}

You're living in a house with a few people. One of your roommates always takes your food and drinks from the fridge without asking, he never cleans up after himself, and he often comes home late at night making a lot of noise, which wakes you up. He's never apologized to you for any of this.

One night, at about four in the morning, he comes home drunk. This wakes you up. You go into the kitchen and you see that he's grabbing your beer and food from the fridge.

\section{Report it to someone:}

You go to your other roommate who holds the lease for the house, and you tell him what's been going on and ask him to deal with the problem. He says he'll deal with it tomorrow and falls back asleep. You leave his room. Your drunk roommate turns on the TV and puts the volume up loud.

\section{Talk it out:}

You say, "Come on, man. It's the middle of the night and you woke me up. You're making a lot of noise and you're eating my food and drinking my beer. That's not what we do. You gotta stop taking my stuff and try to keep it down so I can sleep." He tells you to "shut the fuck up" and turns the TV on loud while eating your food and finishing off your beer.

3. Insult him:

You say, "What the fuck do you think you're doing making so much noise and stealing all my shit? Stop being such an asshole, leave my stuff alone, and quiet the fuck down so I can get some sleep! Fucking douche bag."

He tells you to "shut the fuck up" and turns the TV on loud while eating your food and finishing off your beer.

4. Joke about it:

You jokingly say, “No, no, don't apologize. I didn't want to sleep. I didn't want to eat any of my food. You go ahead and enjoy it. You deserve it for being such a great roommate."

He tells you to "shut the fuck up" and turns the TV on loud while eating your food and finishing off your beer.

5. Shove him:

You push him.

He shoves you back.

6. Hit, punch, kick, or tackle him:

You hit him.

He hits you back.

7. Threaten to hurt him:

You say, "What the fuck do you think you're doing? You looking for a beating? I'm gonna kick the shit out of you if you don't leave my stuff alone and shut the fuck up."

He laughs at you and says, "Yeah right. Let's see what you got, bitch. I'm gonna knock you the fuck out."

8. Ignore it:

You go back to your bed. 
You hear him banging around in the kitchen some more. A few minutes later he turns on the TV and puts the volume up loud.

9. Leave:

You decide to go to a friend's place for the rest of the night. As you're getting ready to leave, he laughs and says, "you better keep it down or you're gonna to wake everybody up". 


\section{SCENE 2 - LINE CUTTER}

You're at the store. There is a long line-up and you're close to the back of it and it's moving slow. You have been waiting in line for a while when a guy with a shopping cart full of items cuts right in front of you in the line.

\section{Report it to someone:}

You tell the store manager. The guy tells the store manager that you're lying. After the store manager leaves, the guy calls you a pussy.

\section{Talk it out:}

You say, "Whoa, buddy, you just cut in front of me. I'm in line here."

He turns and looks at you and then turns back, ignoring you. He starts talking to someone on his cell phone, complaining about the long lines and saying that he just cut in front of some pussy in line.

\section{Insult him:}

You say, "Hey asshole! What the hell are you doing? Get to the back of the line!" He tells you to "go fuck yourself" and stays where he is.

4. Joke about it:

You jokingly say to the other people in line, "Can you believe this guy?"

He tells you to "go fuck yourself" and stays where he is.

\section{Shove him:}

You push him.

He shoves you back.

6. Hit, punch, kick, or tackle him:

You hit him.

He hits you back.

\section{Threaten to hurt him:}

You say, "Hey asshole! What the hell are you doing? Get to the back of the line or I'm gonna knock you out!"

He laughs at you and says, "What are you gonna do? You wanna go? I'm gonna fuckin crush you."

\section{Ignore it:}

You don't say or do anything. He starts talking to someone on his cell phone, complaining about the long lines and saying that he just cut in front of some pussy in line and the guy didn't do anything about it.

9. Leave:

You decide to move to another line. As you're leaving, he starts talking to someone on his cell phone, saying that he just cut in front of some pussy in line and now he's running away. 


\section{SCENE 3 - BEER BUMP}

You're at a bar when out of nowhere a guy bumps into you and spills beer on your shirt. He says "get out of my way" and starts to walk back to his table.

\section{Report it to someone:}

You tell the bar manager and ask him to deal with the guy. The bar manager says there's nothing he can do about it. You go back to the spot in the bar where you were before.

\section{Talk it out:}

You say, "You spill your beer on me and act like it's my fault? Come on. That's not right."

Hey says, "Stop crying about it and get the fuck out of here before I give you something real to cry about."

3. Insult him:

You say, "Hey! You're a fuckin' asshole!"

He says, "What the hell did you say? Get the fuck out of here before you get hurt."

4. Joke about it:

You jokingly say to the people around you, "Did you see that? What's up with that guy? I guess some people just can't handle their beer."

He sees you looking in his direction while you're joking and he gives you the finger.

5. Shove him:

You push him.

He shoves you back.

6. Hit, punch, kick, or tackle him:

You hit him.

He hits you back.

7. Threaten to hurt him:

You say, "Hey, what's your problem? You wanna get punched in the head?"

He says, "Alright asshole, let's go. I'm gonna crack your fuckin head open."

8. Ignore it:

You don't say or do anything.

He starts talking to someone at his table, points back at you, and starts laughing.

9. Leave:

You decide to leave the bar. As you're leaving, he starts talking to someone at his table, points back at you, and starts laughing. 


\section{SCENE 4 - BEER RUN}

You're at a party. A guy there is going out to buy some beer. You ask him to get some beer for you too and give him $\$ 25$. When he returns hours later, he says he doesn't have your beer or your money.

\section{Report it to someone:}

You tell the guy who's hosting the party and ask him to deal with the problem. The host says there's nothing he can do about it, and then gets called away by someone else.

\section{Talk it out:}

You say, "What happened with my beer? I'm gonna need my beer or my money back."

He says, "Well, you're shit out of luck. You're not getting any money and you're not getting any beer."

3. Insult him:

You say, "Listen, I don't care if your mom needs that money for crack. Give me back my money, you piece of shit."

He says, "What the fuck did you just say? You'll shut your fucking mouth and get out of here if you know what's good for you."

\section{Joke about it:}

You jokingly say to the people around you, "What just happened here? Did this guy seriously just steal $\$ 25$ from me? Who is this guy?"

He says, "What the fuck did you just say? You'll shut your fucking mouth and get out of here if you know what's good for you."

\section{Shove him:}

You push him.

He shoves you back.

6. Hit, punch, kick, or tackle him:

You hit him.

He hits you back.

7. Threaten to hurt him:

You say, "Give me my money back or I'll beat the shit out of you."

He says, "What the fuck did you just say? Let's go pussy. I'm gonna knock your fuckin teeth in."

\section{Ignore it:}

You don't say or do anything.

He starts talking to some other people at the party about what he did, points over at you, and starts laughing.

9. Leave:

You decide to leave the party. As you're leaving, he starts talking to some other people at the party about what he did, points over at you, and starts laughing. 


\section{SCENE 5 - THREAT}

You're at a party. A guy walks up to you and says, "You got ten seconds to get out of here or I'm gonna to kick the shit out of you."

\section{Report it to someone:}

You tell the guy who's hosting the party and ask him to deal with the problem. The host tells you to just stay away from the guy, and then gets called away by someone else.

\section{Talk it out:}

You say, "Whoa, take it easy. You don't even know me and this isn't your house. How about you just enjoy the party and don't worry about me?"

He moves closer to you and says, "Clock's ticking, shithead. Better run away while you still can."

3. Insult him:

You say to him, "How small is your dick that you need to be acting like that? Go somewhere else and grow a dick."

He moves closer to you and says, "We'll see how funny you are when I'm kicking your head in. Clock's ticking, shithead. Better run away while you still can."

4. Joke about it:

You jokingly say to the people around you, "Wow, this guy is really not making me feel welcome at this party. Gotta talk to the host about getting a new greeter."

He moves closer to you and says, "We'll see how funny you are when I'm kicking your head in. Clock's ticking, shithead. Better run away while you still can."

5. Shove him:

You push him.

He shoves you back.

6. Hit, punch, kick, or tackle him:

You hit him.

He hits you back.

7. Threaten to hurt him:

You say, "Settle the fuck down and go somewhere else before I take your fucking head off."

He moves closer to you and says, "Wrong choice, bitch. Let's go. I'm gonna fuck you up."

\section{Ignore it:}

You don't say or do anything.

He moves closer to you and says, "Clock's ticking, shithead. Better run away while you still can."

9. Leave:

You decide to leave the party.

As you're leaving, he says, "Only a few seconds left - better run, pussy!" 


\section{SCENE 6 - UNWANTED GUEST}

You're at a party. There is a guy at the party who is bothering people and won't leave. Everyone seems to want this guy to leave. He is bothering the woman who is hosting the party. She asks him to leave but he refuses and continues to be a jerk.

\section{Report it to someone:}

You tell another guy at the party and ask him to deal with the problem.

He says there's nothing he can do about it, and then gets called away by someone else.

2. Talk it out:

You say to him, "Hey, bud, she wants you to leave. It's her place, so her call, right? And you don't seem to be liking the party anyway. You should go." He looks at you, laughs, and says, "Why is this guy talking to me? Who does this fucking guy think he is? Shut up and get away from me."

3. Insult him:

You say to him, "Hey, douche bag, she wants you to leave. Stop being such a dick and get the fuck out of here."

He looks at you, laughs, and says, "Why is this guy talking to me? Who does this fucking guy think he is? Shut up and get away from me, pussy, before I smack you in the head."

\section{Joke about it:}

You jokingly say to the people around you, "Who made the mistake of inviting this guy to the party?"

He looks at you and says, "You got something to say there, pussy?"

\section{Shove him:}

You push him.

He shoves you back.

6. Hit, punch, kick, or tackle him:

You hit him.

He hits you back.

\section{Threaten to hurt him:}

You say to him, "Hey, douche bag, she wants you to leave. Stop being such a dick and get out of here, or I'll throw you out."

He looks at you, laughs, and says, "You're gonna throw me out? You?! Go for it. I'm gonna beat the shit out of you."

8. Ignore it:

You don't say or do anything.

He continues bothering the host and other people, and the host keeps telling him to leave.

\section{Leave:}

You decide to leave the party.

As you're leaving, he continues bothering the host and other people, and the host keeps telling him to leave. 


\section{SCENE 7 - OBNOXIOUS GUY IN LINE}

You're waiting in line in the store. The person behind you is talking to his friend really loudly and rudely. He is standing very close to you and he keeps bumping you with his arms as he moves around while talking to his friend.

\section{Report it to someone:}

You tell the store manager. The store manager asks the guy to be more quiet. The guy says okay, and the store manager leaves. The guy taps you on the shoulder and asks, "You gonna go cry to your mother next?" and starts laughing with his friend and goes right back into talking loudly and rudely and getting in your space.

\section{Talk it out:}

You say to him, "Come on, man, what are you doing? You gotta stop talking like that and give me some room."

He laughs at you and says, "Oh yeah, well, you gotta turn around and mind your own fucking business."

\section{Insult him:}

You say to him, "What are you doing, asshole? Back the fuck up and save your stupid fucking stories for out in the parking lot when you and your buddy are jackin each other off."

He says, "Nobody's talking to you, pussy. Shut the fuck up, turn around, and mind your own fucking business, if you know what's good for you."

4. Joke about it:

You jokingly say to the people around you, "Nice way to talk in the store with women and children around. Real classy."

He says, "Nobody's talking to you, pussy. Shut the fuck up and mind your own fucking business."

\section{Shove him:}

You tell him to shut up and push him.

He shoves you back.

6. Hit, punch, kick, or tackle him:

You tell him to shut up and hit him.

He hits you back.

7. Threaten to hurt him:

You say, "What are you doing, asshole? Back the fuck up and save your stupid fucking stories for out in the parking lot when you and your buddy are jackin each other off. Bump into me one more time and I'll kick your ass."

He says, "What are you gonna do, pussy? I'm gonna smash your fuckin face in."

8. Ignore it:

You don't say or do anything.

The guy says something about you to his friend and they both start laughing.

9. Leave:

You decide to leave.

As you're leaving, the guy says something about you to his friend and they both start laughing. 


\section{SCENE 8 - INTIMATE PARTNER VIOLENCE}

You are at a party. You notice a couple at the party fighting, and the guy seems to be very angry at the woman. He starts yelling at her and calling her names, and accusing her of cheating on him. Then the guy slaps the woman in the face.

\section{Report it to someone:}

You call the police and report it. They say they'll send an officer later and hang up.

2. Talk it out:

You say to him, "Did you really just slap her? That's really messed up, man. You gotta leave."

He says, "Fuck off and mind your own business. You should worry about what your own slutty bitch is doing right now."

3. Insult him:

You say to him, "What kind of fuckin psycho hits a woman? What's your fucking problem, man? Leave her alone, you piece of shit."

He says, "Fuck off and mind your own business. You should worry about what your own slutty bitch is doing right now."

\section{Joke about it:}

You say to the people around you, "Did everybody see that? Who hits a woman? What's wrong with this psycho?"

He says, "Fuck off and mind your own business. You should worry about what your own slutty bitch is doing right now."

\section{Shove him:}

You push him.

He shoves you back.

6. Hit, punch, kick, or tackle him:

You hit him.

He hits you back.

7. Threaten to hurt him:

You say to him, "What the fuck are you doing? Leave her alone or I will beat the living shit out of you."

He says, "Fuck off and mind your own business. I'm gonna knock you out as soon as I'm done with this whore."

8. Ignore it:

You don't say or do anything.

He continues to yell at her and he hits her again.

9. Leave:

You decide to leave.

As you're leaving, he continues to yell at her and he hits her again. 


\section{SCENE 9 - INTERLOPER}

You're at a bar standing beside your girlfriend/wife when a guy walks up to her, puts his arm around her, and starts trying to pick her up. He acts like you aren't even there.

\section{Report it to someone:}

You tell the bar manager and ask him to deal with the guy. The bar manager says there's nothing he can do about it. The guy tells your girlfriend/wife that you're a loser and asks her to dance.

\section{Talk it out:}

You say to him, "Buddy, what are you doing? You know she's with me. Go talk to someone else."

He ignores you, steps between you and your girlfriend/wife, turns his back to you, tells her that you're a loser, and asks her to dance.

\section{Insult him:}

You say to him, "Are you a fucking idiot? What's wrong with you? Get the fuck out of here and find your own woman."

He ignores you, steps between you and your girlfriend/wife, turns his back to you, tells her that you're a loser, and asks her to dance.

4. Joke about it:

You jokingly say, “That's right. Come over here and hit on the girl who's with someone already. Real fuckin' smart."

He ignores you, steps between you and your girlfriend/wife, turns his back to you, tells her that you're a loser, and asks her to dance.

5. Shove him:

You push him.

He shoves you back.

6. Hit, punch, kick, or tackle him:

You hit him.

He hits you back.

7. Threaten to hurt him:

You say to him, “Are you a fucking idiot? What's wrong with you? Start showing some fuckin respect or I'll kick the shit out of you."

He says, "Yeah, what are you gonna do? I'll fucking punch you out. Listen, you're gonna go get some drinks for the lady and me, and then stay the fuck out of our way."

8. Ignore it:

You don't say or do anything.

He steps between you and your girlfriend/wife, turns his back to you, tells her that you're a loser, and asks her to dance.

9. Leave:

You decide to leave.

As you and your girlfriend/wife are leaving, the guy says to your girlfriend/wife, "Don't leave with that loser. You're too hot for that guy. You can do so much better." 


\section{SCENE 10 - DISRESPECTING YOUR GIRLFRIEND/WIFE}

You're at a bar. You overhear a guy talking about your girlfriend/wife. He is saying that she looks like a real slut and that she probably loves to suck cock. He says he bets he can get her to give him a blowjob in the washroom.

\section{Report it to someone:}

You tell the bar manager and ask him to deal with the guy. The guy tells the bar manager that you're lying. After the bar manager leaves, the guy says that you'll probably want to give him a blowjob too.

2. Talk it out:

You say, “That's my girlfriend you're talking about. Come on, man, have some respect."

He says, "Hey relax man - just kidding around." But a few seconds later, he says, "Spits or swallows? I bet she swallows."

3. Insult him:

You say, "What's your fucking problem, man? I think maybe you're the cocksucker. Go jam a dick in your mouth already and shut the fuck up."

He says, "Hey, relax man. Don't worry. I don't want to keep her. She can still go home with you after she blows me a few times."

4. Joke about it:

You jokingly say to nobody in particular, "Classy place. I like the energy. This creepy guy over here talking shit about the women. Nice touch. Makes you feel welcome. Well done."

He says, "Spits or swallows? I bet she swallows."

5. Shove him:

You push him.

He shoves you back.

6. Hit, punch, kick, or tackle him:

You hit him.

He hits you back.

7. Threaten to hurt him:

You say, "Hey asshole! Watch your fucking mouth! That's my girlfriend you're talking about. If I hear you talking like that again, I'll kick your ass."

He says, "Yeah, you wanna go? I'm gonna stomp your fucking face and then your lady's gonna blow me in your car."

8. Ignore it:

You don't say or do anything.

He says, "Spits or swallows? I bet she swallows."

9. Leave:

You decide to leave.

As you and your girlfriend/wife are leaving, he says, "Spits or swallows? I bet she swallows." 


\section{Appendix B}

\section{The Evaluation of Violence Questionnaire (EVQ)}

RESPONSE SCALES: Very negative, A bit negative, A bit positive, Very positive Very unpleasant, A bit unpleasant, A bit pleasant, Very pleasant Very bad, A bit bad, A bit good, Very good

INSTRUCTIONS: Please rate how you think or feel about each item. For example, how good or bad would punching someone be?

\begin{tabular}{|c|c|c|}
\hline \# & Item & Response scale \\
\hline 1 & $\begin{array}{l}\text { You hitting (for example, punching or kicking) a guy who hurts } \\
\text { someone you care about. }\end{array}$ & $\begin{array}{l}\text { Negative vs. } \\
\text { positive }\end{array}$ \\
\hline 2 & $\begin{array}{l}\text { You hitting (for example, punching or kicking) a guy who steals from } \\
\text { you. }\end{array}$ & $\begin{array}{l}\text { Negative vs. } \\
\text { positive }\end{array}$ \\
\hline 3 & $\begin{array}{l}\text { You hitting (for example, punching or kicking) a guy who runs a red } \\
\text { light and almost hits you with his car. }\end{array}$ & $\begin{array}{l}\text { Unpleasant vs. } \\
\text { pleasant }\end{array}$ \\
\hline 4 & $\begin{array}{l}\text { You hitting (for example, punching or kicking) a guy who makes you } \\
\text { look stupid. }\end{array}$ & Bad vs. good \\
\hline 5 & $\begin{array}{l}\text { You hitting (for example, punching or kicking) a guy who tries to } \\
\text { make you look weak. }\end{array}$ & $\begin{array}{l}\text { Unpleasant vs. } \\
\text { pleasant }\end{array}$ \\
\hline 6 & You hitting (for example, punching or kicking) a guy you hate. & Bad vs. good \\
\hline 7 & You threatening to physically hurt a guy who tries to hurt you. & Bad vs. good \\
\hline 8 & $\begin{array}{l}\text { You threatening to physically hurt a guy who disrespects someone } \\
\text { you care about. }\end{array}$ & $\begin{array}{l}\text { Negative vs. } \\
\text { positive }\end{array}$ \\
\hline 9 & You threatening to physically hurt a guy who disrespects you. & $\begin{array}{l}\text { Unpleasant vs. } \\
\text { pleasant }\end{array}$ \\
\hline 10 & You threatening to physically hurt a guy who owes you money. & Bad vs. good \\
\hline 11 & You threatening to physically hurt a guy who keeps mouthing off. & Bad vs. good \\
\hline 12 & $\begin{array}{l}\text { You threatening to physically hurt a guy who says bad stuff about } \\
\text { you behind your back. }\end{array}$ & $\begin{array}{l}\text { Negative vs. } \\
\text { positive }\end{array}$ \\
\hline 13 & You threatening to physically hurt a guy who makes you mad. & $\begin{array}{l}\text { Unpleasant vs. } \\
\text { pleasant }\end{array}$ \\
\hline 14 & You threatening to physically hurt a guy who acts tough. & $\begin{array}{l}\text { Negative vs. } \\
\text { positive }\end{array}$ \\
\hline 15 & $\begin{array}{l}\text { You using a weapon (for example, a baseball bat, knife, or gun) on a } \\
\text { guy who has sex with your girlfriend/wife or boyfriend/husband. }\end{array}$ & $\begin{array}{l}\text { Unpleasant vs. } \\
\text { pleasant }\end{array}$ \\
\hline 16 & $\begin{array}{l}\text { You using a weapon (for example, a baseball bat, knife, or gun) on a } \\
\text { guy who wrecks your stuff on purpose. }\end{array}$ & $\begin{array}{l}\text { Negative vs. } \\
\text { positive }\end{array}$ \\
\hline 17 & $\begin{array}{l}\text { You using a weapon (for example, a baseball bat, knife, or gun) on a } \\
\text { guy when you're scared. }\end{array}$ & Bad vs. good \\
\hline
\end{tabular}


Note. In our studies, we have been randomizing the order in which the items are presented.

SCORING: Responses to each item are scored from 1 to 4 (e.g., very negative $=1$, a bit negative $=2$, a bit positive $=3$, very positive $=4$ ), and averaged to compute the total score. 


\section{Appendix C}

\section{Attention Check Questions}

These items were randomly placed with their corresponding response scales among the EVQ to identify participants who were not attending to or comprehending the survey questions.

1. Please select "very good"

2. Please select "a bit unpleasant" 


\section{Appendix D}

\section{Manipulation Check Questions}

Please answer the following questions about the informational message you were asked to read on the pages with the photographs

Which of the following was in the message you read on the pages with the photographs?

a) The Grand Canyon is considered to be one of the seven wonders of the natural world.

b) Violence can lead to you getting arrested, getting a criminal record, and going to prison.

c) Using violence can defend you and people you care about from getting injured by an attacker.

Which of the following was in the message you read on the pages with the photographs?

a) Different parts of the Grand Canyon have different climates.

b) Violence - whether or not you started it — makes enemies and gives people a reason to want to hurt you.

c) Sometimes violence really is the best option.

Which of the following was in the message you read on the pages with the photographs?

a) The Grand Canyon is one of the world's most popular natural tourist attractions.

b) Violence can lead to innocent people getting hurt, like your friends or family.

c) Violence can prove that you're strong and won't let people push you around. 


\section{Appendix E}

\section{Experimental Demand Question}

Do you think the message you read at the beginning changed how you reacted to the conflict situations?

a) The message changed how I answered and it changed how I really think about violence.

b) The message changed how I answered, but it didn't change how I really think about violence.

c) The message didn't change how I answered. 


\section{Appendix F}

\section{Demographic Questions}

How old are you? (17 years or younger, 18-20, 21-25, 26-30, 31-35, 36-40, 41-50, 51-60, 61 years or older)

What is your gender? (Male, Female, Other)

In what country are you currently living? (Canada, United States, Other)

What is your current relationship status? (Single, In a romantic relationship, Living with a romantic partner, Married, Separated/divorced/widowed)

Who are you most sexually attracted to? (Women, Men, Both women and men equally, other)

Are you fluent in English? (Yes, No) 


\title{
Appendix G
}

\author{
Evaluation of Violence Manipulations
}

\section{PRO-VIOLENCE CONDITION}

\section{MESSAGE}

Please carefully read the message below. You will be asked to answer some questions about this message later on.

Violence is when someone threatens to use or actually uses physical force to try to hurt or kill another person. For example:

- hitting someone,

- using a weapon to hurt or kill someone, or

- threatening to hit or use a weapon on someone

There are times in life where violence is the best or only option. At these times, violence can be necessary and may be the best choice.

\section{Picture this:}

A threatening man approaches you and an important woman in your life (for example, wife/girlfriend/mother/sister/friend, etc.). He says really rude, insulting, and threatening things about her. You tell him to stop, and you and the woman try to walk away, but he punches you and grabs her.

Now consider some of the good things that could happen if you defended yourself and the woman by fighting back: 
- You fight off the attacker

○ You keep you and the woman from getting serious injuries, like

- Broken bones; for example, you don't get a broken nose or jaw

- Brain damage; for example, you don't get a concussion

- You and the woman don't get killed

- You prove that you're strong and won't let people push you around

○ People won't think you're weak and scared

- People will think twice about to messing with you

- You will be treated with more respect
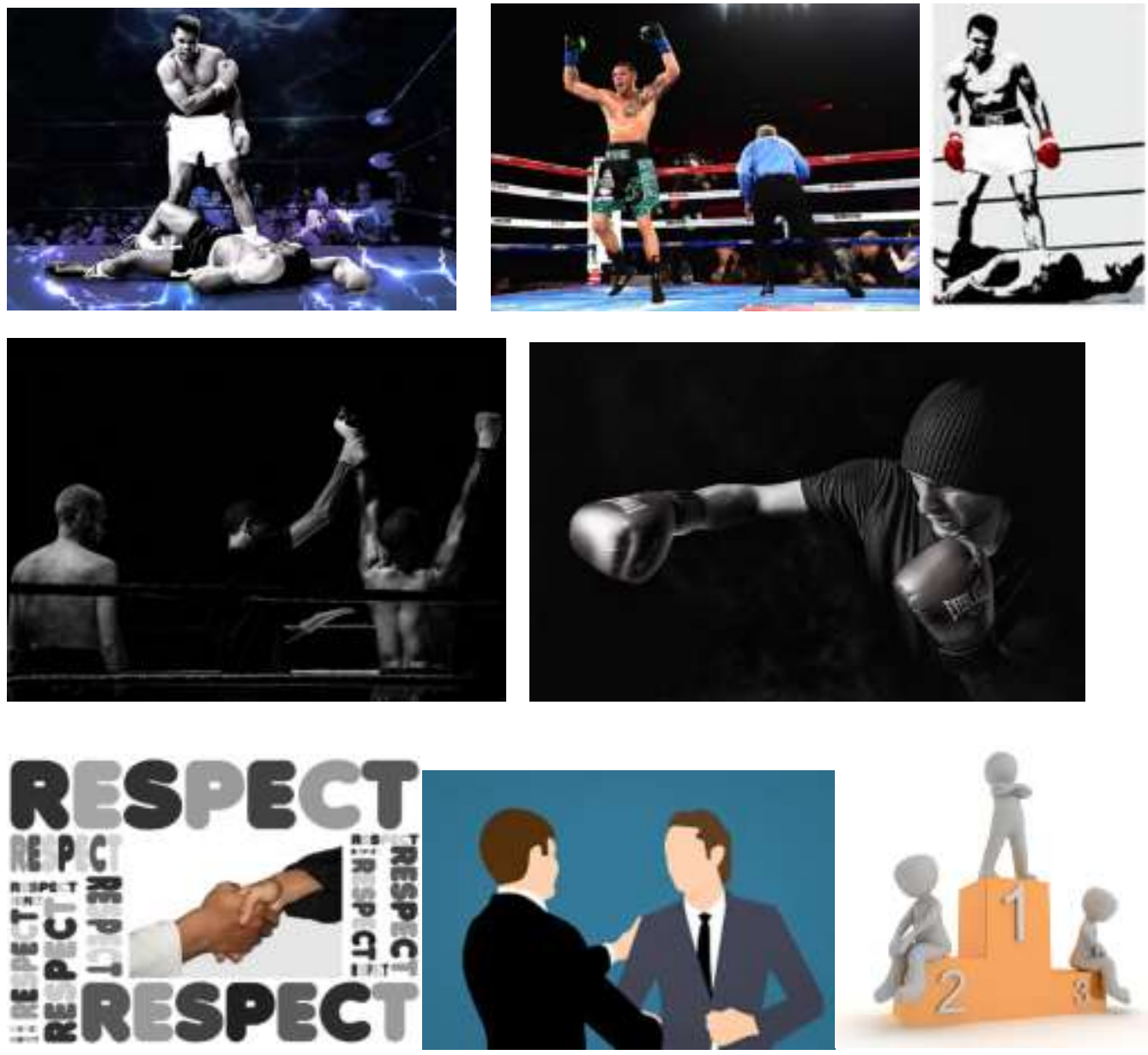
- You will be admired by those around you

○ Loved ones will think you are a hero

○ Others will feel safe with you around to protect them

- Women will find you attractive
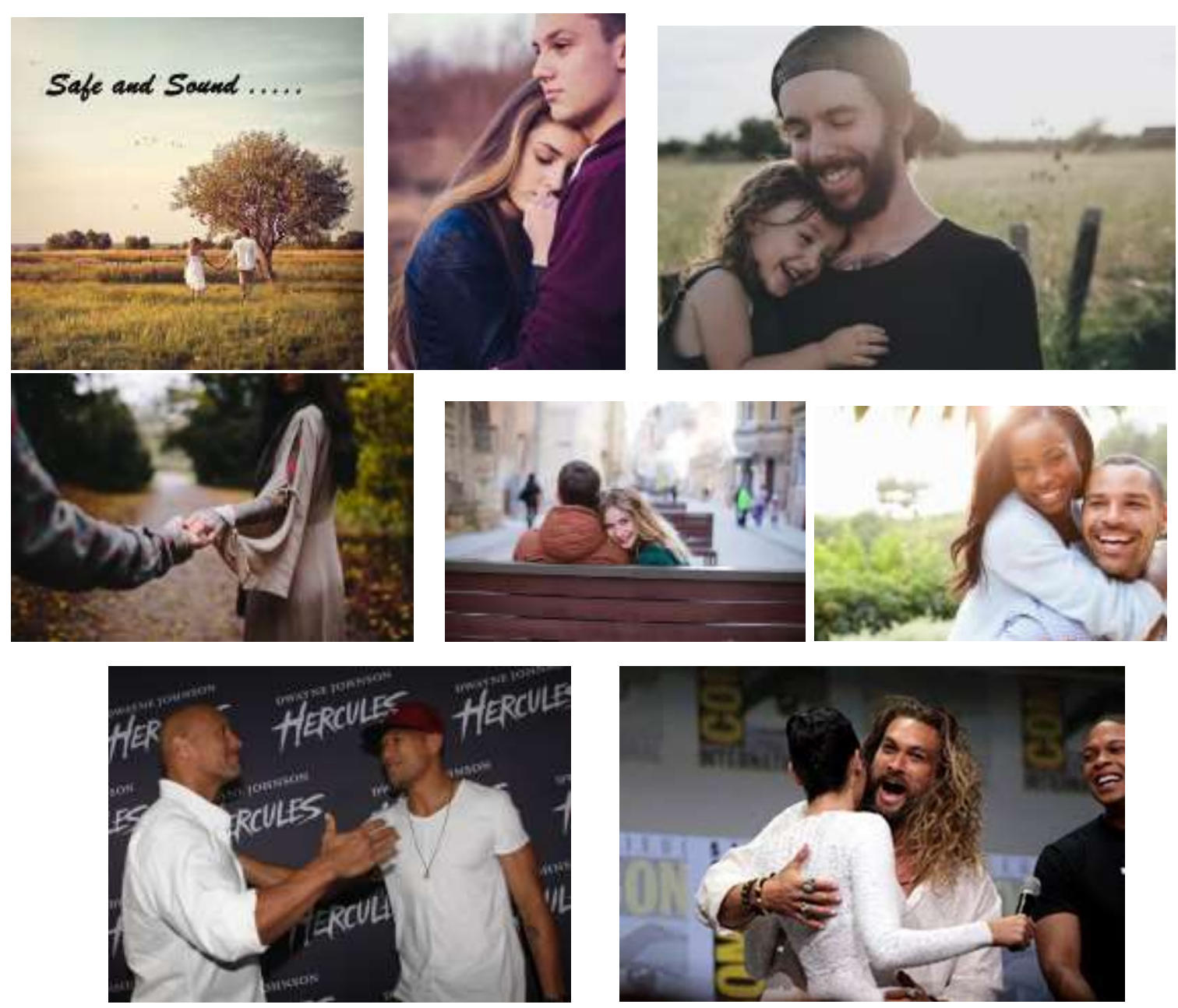
- You defend your reputation and self-respect

○ You feel more confident

○ You know for next time that you can and will fight when you have to
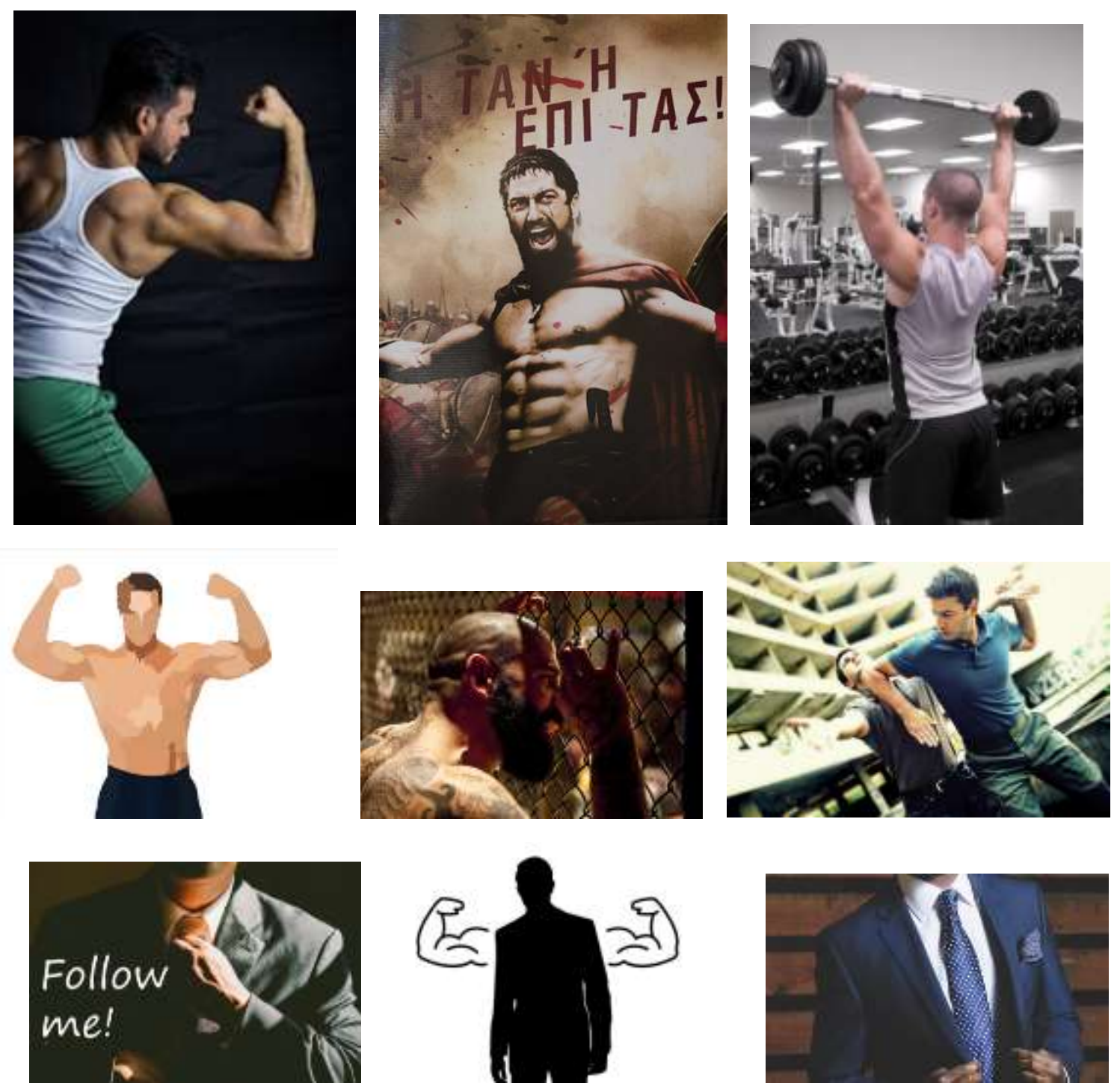
- You protect your things and property (for example, your phone and any items in the purse)

○ You save your things from getting stolen or broken

○ You don't have to waste your money and time buying things to replace what was broken or stolen from you

○ You save yourself the hassle of making insurance claims
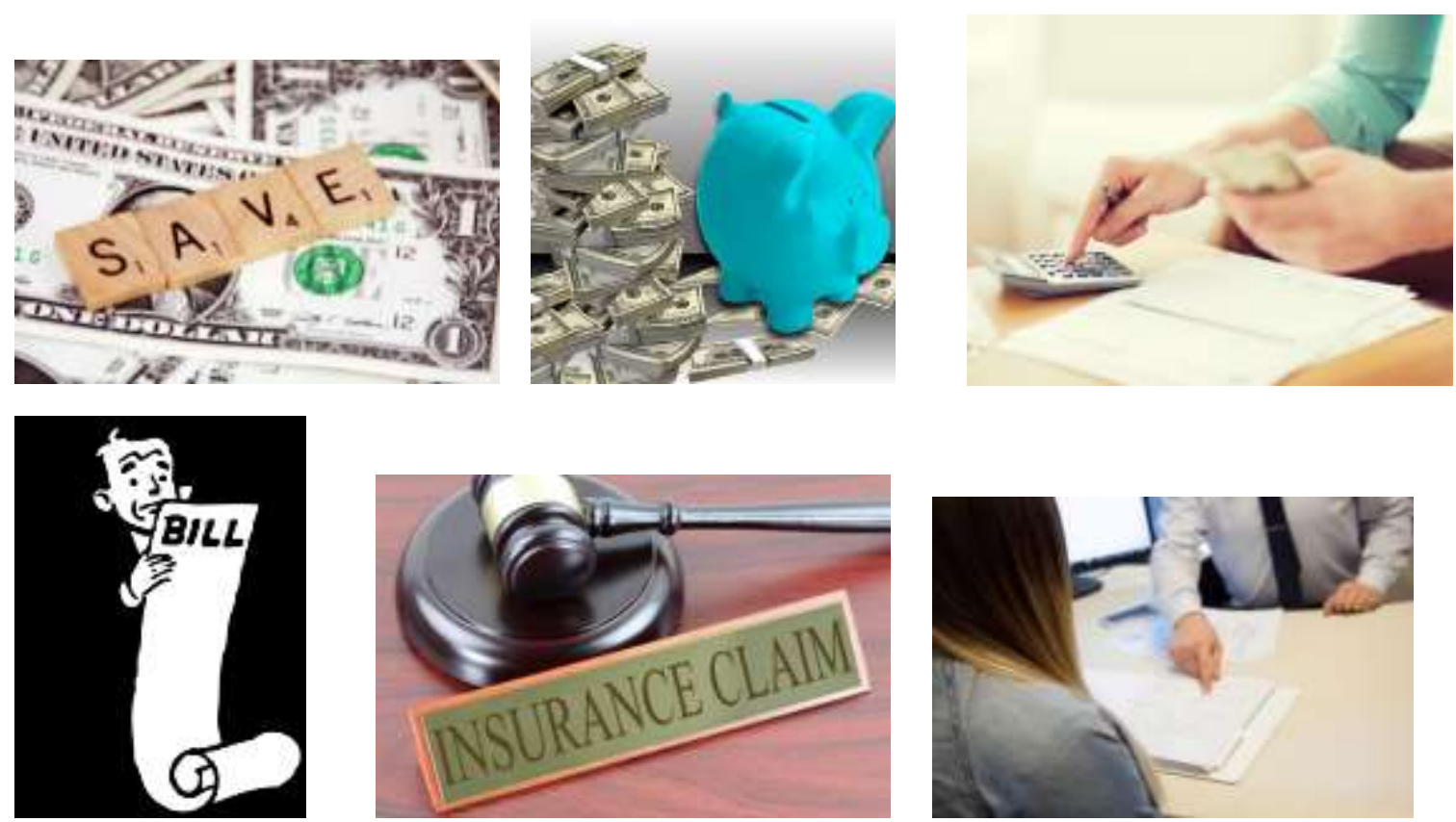
Violence may not always be the answer, but sometimes violence really is the best option

When in danger, using violence can keep your loved ones and you safe, make people respect and admire you, show that you respect yourself and those around you, and stop people from taking advantage of you. 


\section{ANTI-VIOLENCE CONDITION}

\section{MESSAGE}

Please carefully read the message below. You will be asked to answer some questions about this message later on.

Violence is when someone threatens to use or actually uses physical force to try to hurt or kill another person. For example:

- hitting someone,

- using a weapon to hurt or kill someone, or

- threatening to hit or use a weapon on someone.

In extreme cases violence may be necessary; for example, to prevent oneself or others from being physically harmed (self-defence). But, for most of us, most of the time, violence is not necessary. Unlike in the movies, violence causes problems for everyone involved.

\section{Picture this:}

A guy has said or done something bad to you that makes you feel angry. You react by threatening to hit him. He accepts your challenge and is ready to fight. You push him. He pushes you back. You start fighting.

Now consider some of the bad things that could happen: 
- You get arrested, get a criminal record, and go to prison

$\circ$ You have a hard time getting or keeping a good job because of your criminal record

- Your family feels ashamed

- You lose income from missed workdays, and you have to pay extra expenses like paying a lawyer

- You have to leave your life behind (family, friends, job, school) while you're locked up in prison
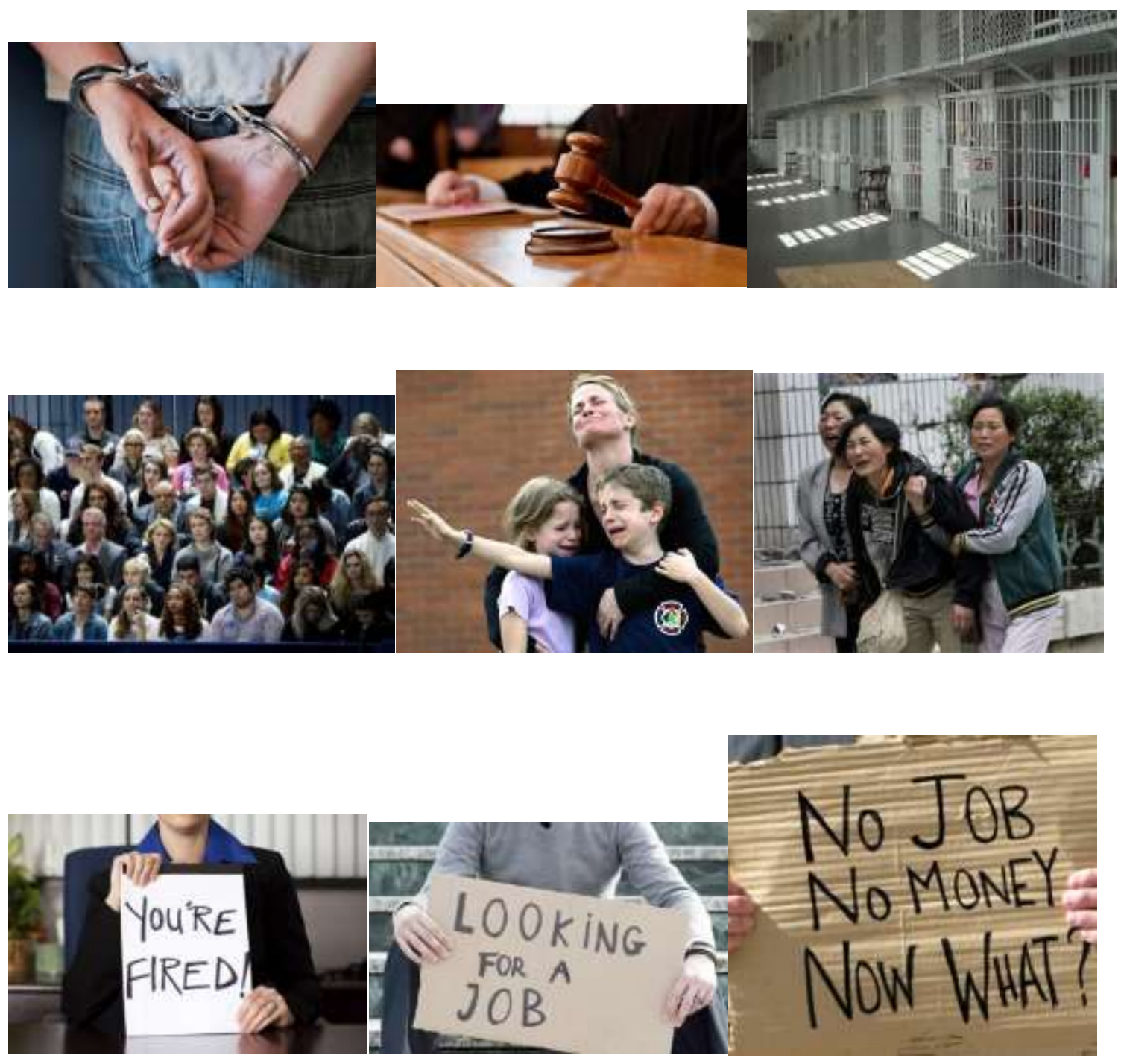


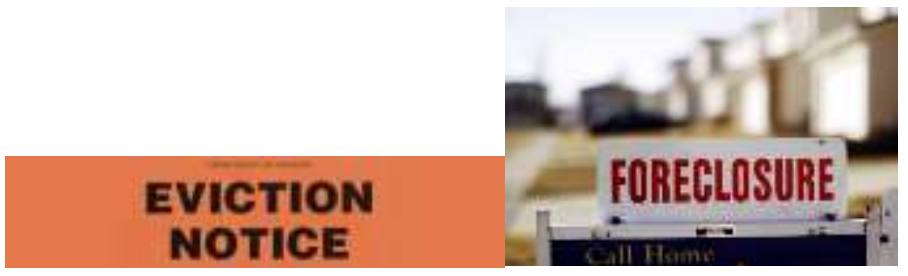


- You get hurt

○ Broken bones; for example, you break your hand by punching

○ Damaged joints; for example, your knee gets damaged

- Brain damage; for example, you get a concussion

- Eye injuries; for example, you lose sight in one eye

- Spinal injury; for example, you get paralyzed

- You die

- You seriously injure or kill the guy
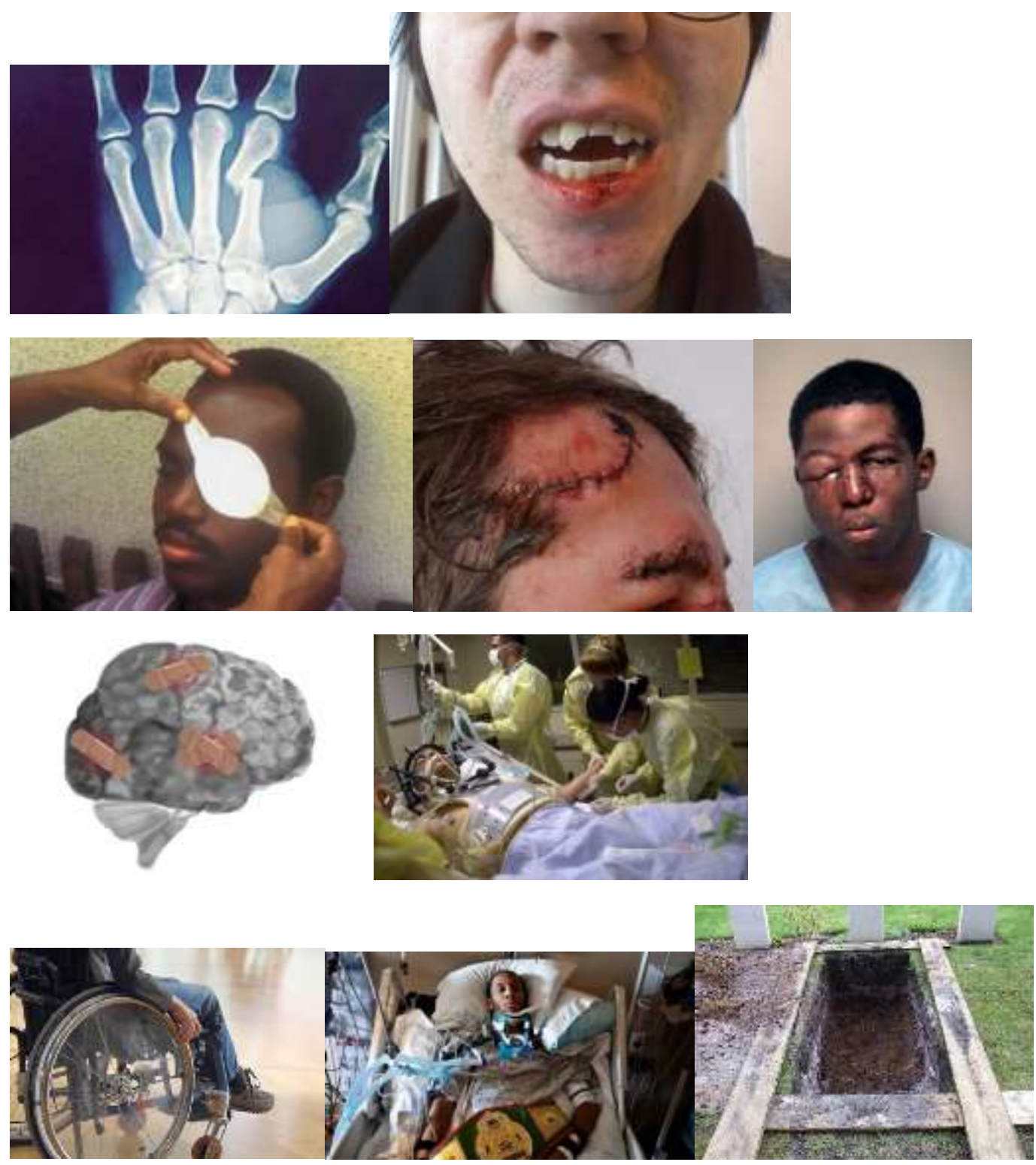
- Innocent people get hurt

○ Bystanders get hit by accident

- Your friends or family are targets of acts of revenge

- Start a cycle of revenge and retaliation that keeps getting worse

- He pulls a weapon, like a knife or a gun

○ He gets his friends involved

- He damages your stuff, like your car or house

$\circ$ He goes after your friends or family

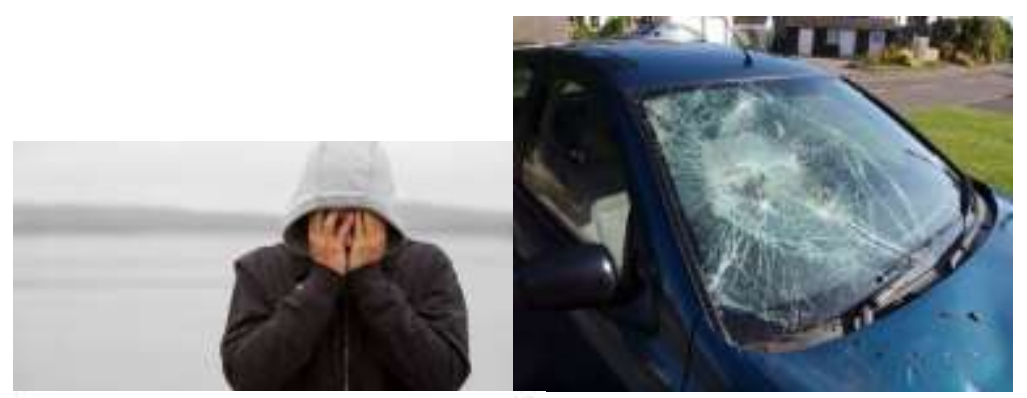

\section{WE ARE WATCHING YOU}

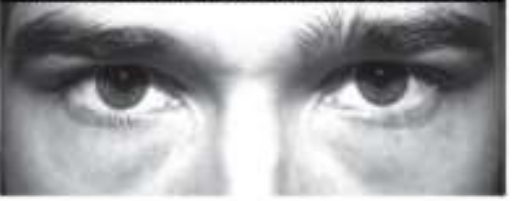


Violence - whether or not you started it - makes enemies and gives people a reason to want to hurt you. Violence starts a cycle that is hard to break.

The more enemies you make, the more time and energy you have to spend being on guard worrying about who might attack you and how to protect yourself.

Violence is a "lose-lose" situation, with negative consequences for everyone involved. 


\section{CONTROL CONDITION}

\section{MESSAGE}

Please carefully read the message below. You will be asked to answer some questions about this message later on.

The Grand Canyon is considered to be one of the seven wonders of the natural world.

The Grand Canyon is a steep-sided gorge carved by the Colorado River. Located in the state of Arizona, the canyon is 277 miles long, up to 18 miles wide, and one mile deep. Many layers of rocks are exposed in the canyon, showing the region's geological history. The canyon is also known for its overwhelming size and colorful landscape.

Picture this:

You are visiting the Grand Canyon and taking in the sights.

Now consider some of the things you could learn, see, and do: 
- History of the Grand Canyon

- The Colorado River began carving the Grand Canyon 5 to 6 million years ago

- In 1869, John Wesley Powell led the first expedition down the Grand Canyon

- President Roosevelt advocated for the preservation of the canyon when he was in office

- In 1919, the Grand Canyon became a national park
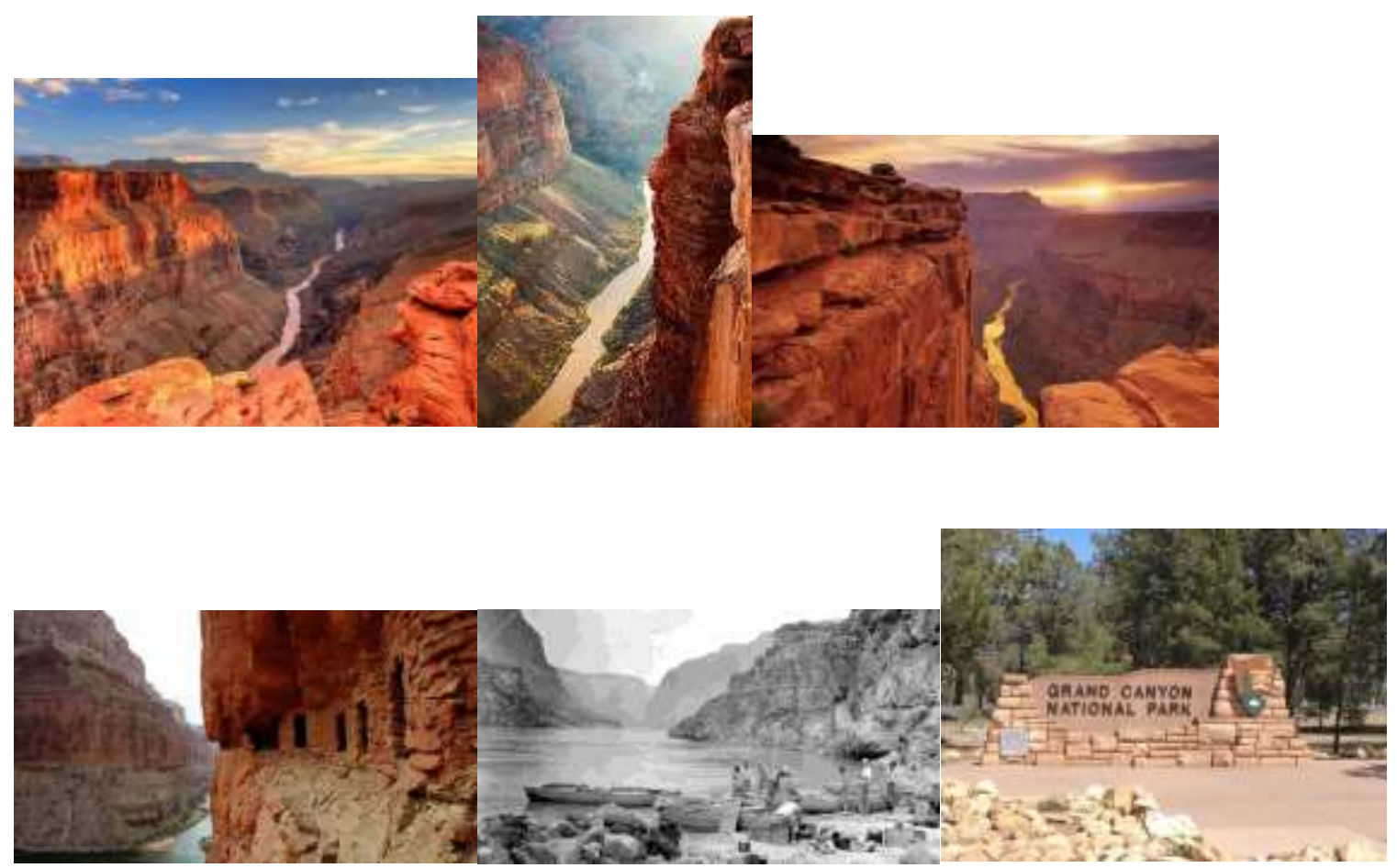
- Grand Canyon rocks

- Nearly 40 different types of rocks can be seen in the canyon

- The oldest rocks are at the bottom of the canyon and the youngest rocks are at the top

- The oldest type of rock in the canyon is granite

$\circ$ The youngest type of rock in the canyon is limestone
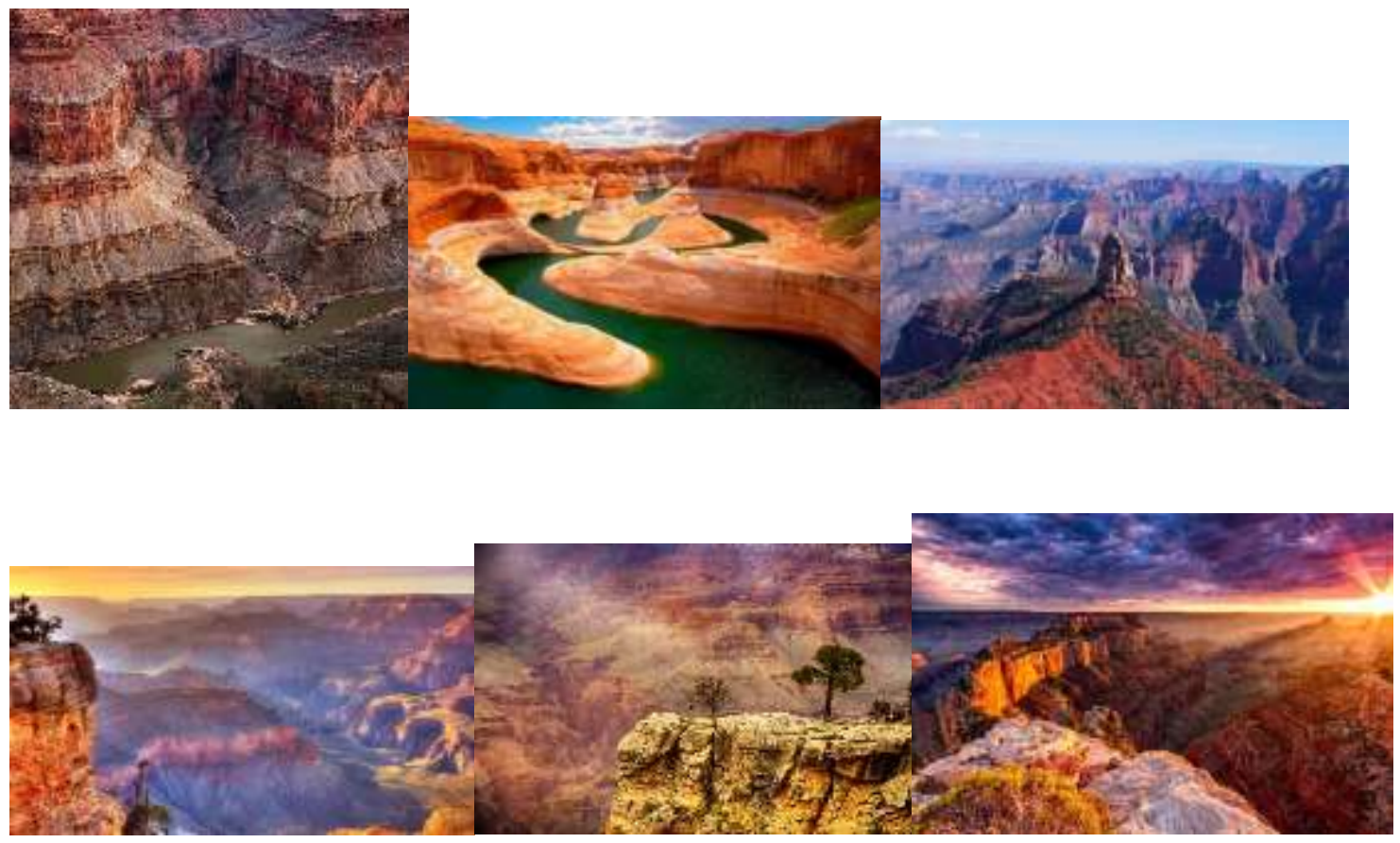
- Grand Canyon climate

- Different parts of the canyon have different climates

- Nights are cool on the Grand Canyon's South Rim

- The North Rim can receive snow throughout most of the year

○ The Inner Canyon (below the rim) is much warmer and can reach very high temperatures
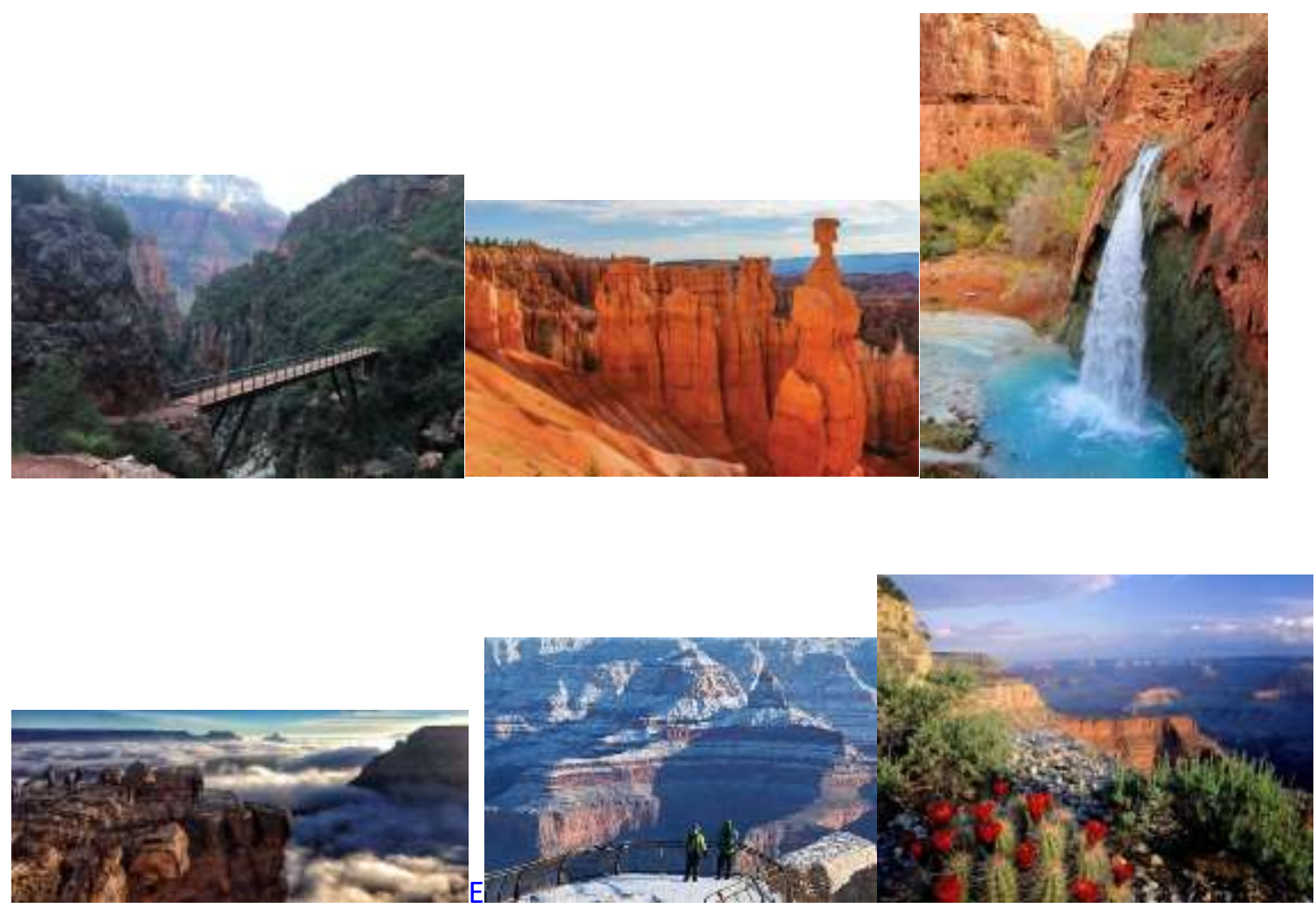
- Things to do at the Grand Canyon

○ Sightseeing

- Hiking

○ Rafting

$\circ$ Camping
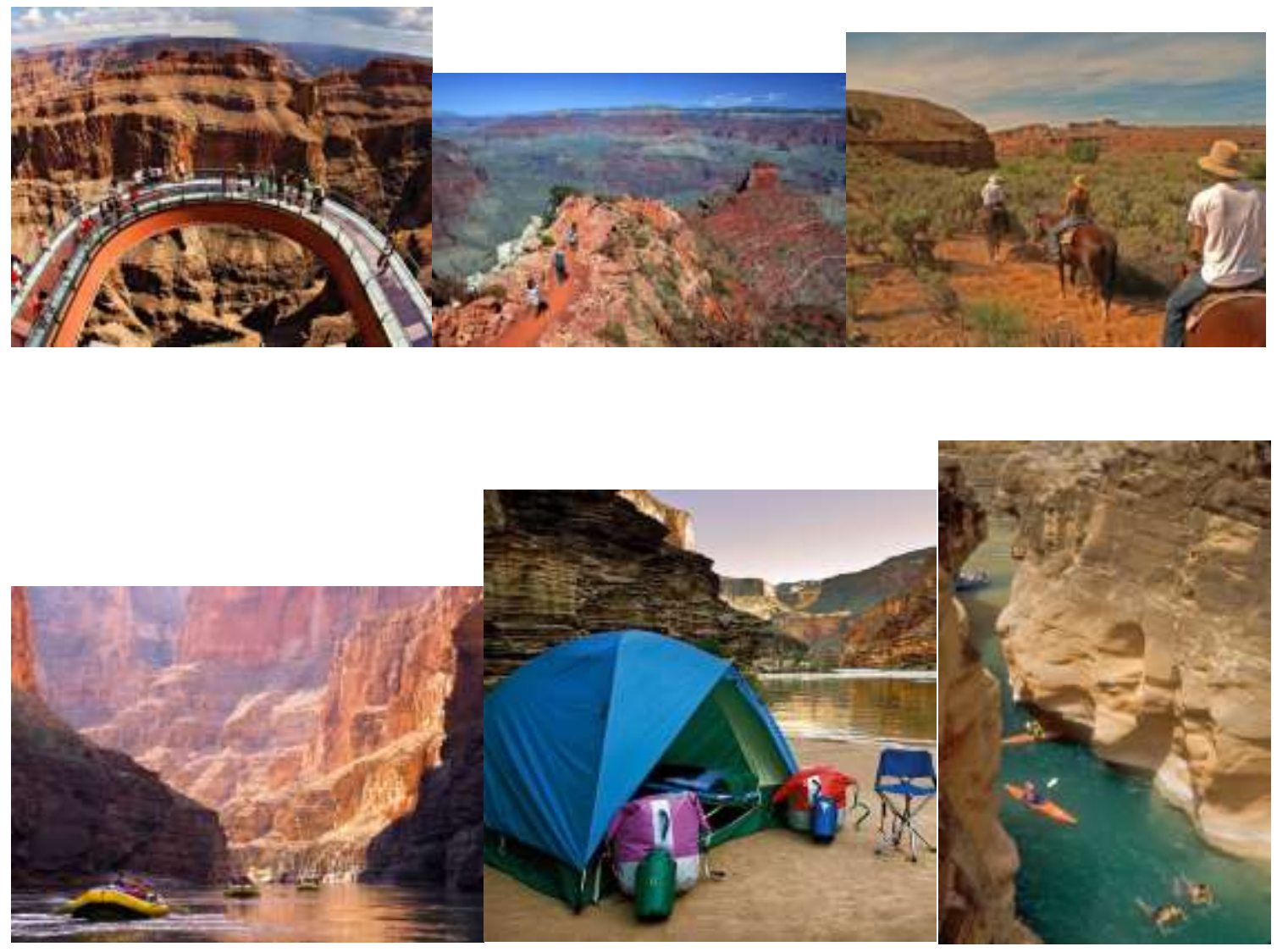
The Grand Canyon is an important geological site, as well as one of the world's most popular natural tourist attractions with over five million visitors each year.

If you plan to visit, you would want to plan ahead to make sure you are well prepared and can make the most of your visit.

The Grand Canyon is an impressive site with something for everyone to enjoy. 


\section{Appendix $\mathbf{H}$}

\section{Consent Form}

\section{Carleton \\ U N I VER S I T Y \\ Canada's Capital University}

\section{Research Consent Form}

Name and Contact Information of Researchers: This study is led by Lynden Perrault (lyndenperrault@cmail.carleton.ca) under the supervision of Dr. Kevin Nunes (email: kevin.nunes@carleton.ca, phone: 613-520-2600, ext. 1545).

Project Title: A Study on Attitudes and Violent Behaviour

\section{Project Sponsor and Funder:}

Social Sciences and Humanities Research Council Insight Development Grant

\section{Carleton University Project Clearance}

Clearance \#: 111178

Date of Clearance: August 9, 2019

\section{Invitation}

You are invited to participate in a study concerning the relationship between attitudes and violent behaviour. The information in this form is intended to help you understand what we are asking of you so that you can decide whether you agree to participate in this study. Your participation in this study is voluntary, and a decision not to participate will not be used against you in any way. As you read this form, and decide whether to participate, please ask all the questions you might have, take whatever time you need, and consult with others as you wish.

\section{What is the purpose of this study?}

To test the relationship between attitudes and violent behaviour.

\section{What will I be asked to do?}

If you agree to participate in this study, we will ask you to:

- Read information and view photos regarding various topics, including violence 
- Asked to answer some questions about your opinions and behaviours regarding violence

- Read conflict situations (for example, a man insults you or your romantic partner) and asked how you would deal with the conflict (for example, by ignoring him, punching him, or speaking with him)

- This will take about 20 minutes.

\section{Who is eligible to participate in this study?}

Males between the ages of 18 and 40 who live in North America and are fluent in English.

\section{Risks and Inconveniences}

Note that the questions ask about violence and you will read and see pictures about violence. The dialogue in the conflict situations is also graphic - a lot of swearing, insults, hostility, aggression and violence - which may cause frustration, anger, and distress for some participants. You are free to refuse to answer any of the questions or stop the survey at any time without penalty. The debriefing form at the end of the study provides contact information for local support services that you may contact if you need or want help.

\section{Possible Benefits}

You may not receive any direct benefit from your participation in this study. However, your participation may allow researchers to better understand attitudes and violent behaviour.

\section{Compensation/Incentives}

You will be compensated for your time, except if you answered without paying attention (for example, giving the wrong answer for the attention-check questions, clicking the same button for every question, or finishing the survey much faster than most other participants), if you did not answer any of the few questions that require an answer (you will see if you have skipped any required questions and be asked again to answer them), if you withdrew from the survey before the end of it, or if you do not meet the eligibility criteria. The amount and conditions of compensation are specified in your agreement with the company managing this survey panel.

\section{No waiver of your rights}

By signing this form, you are not waiving any rights or releasing the researchers from any liability. 


\section{Withdrawing from the study}

Your participation in this study is entirely voluntary. At any point during the study, you have the right to not complete certain questions, or to withdraw. However, as mentioned above, you would not receive payment if you answered without paying attention, if you did not answer any of the few questions that require an answer, or if you withdrew from the survey before the end of it. An option to withdraw from the survey will be presented at the bottom of each page of the survey. The researchers will not use your data if you choose to withdraw. Please note that it is not possible to withdraw your data after you have completed the survey because your responses are anonymous and the researchers will not be able to identify which responses were yours.

\section{Confidentiality}

The data collected in this experiment is strictly confidential. No information that could be used to identify you can be connected with your survey responses, so your answers will be anonymous. In other words, nobody will be able to link your answers to your identity and we will not know who said what. IP addresses or any other information that could identify you will NOT be collected. Research records may be accessed by the Carleton University Research Ethics Board in order to ensure continuing ethics compliance. The information you provide will be used only for research and teaching purposes, such as presentations at conferences and articles in scientific journals.

\section{Data Retention}

Your data will be stored and protected by Qualtrics. The data for this study will be removed from the Qualtrics server after six months and will be permanently stored on password protected computers and data keys in Dr. Kevin Nunes' lab at Carleton University and will be accessible only to the researchers working on this project and related future research. Please note that because Qualtrics is based in the USA, the United States Patriot Act permits U.S. law enforcement officials, for the purpose of an antiterrorism investigation, to seek a court order that allows access to recorded data. However, because the data being collected are anonymous (i.e., no identifying information is connected to survey responses), law enforcement officials would not be able to identify your responses.

\section{New information during the study}

In the event that any changes could affect your decision to continue participating in this study, you will be promptly informed.

\section{Ethics review}

This project was reviewed and cleared by the Carleton University Research Ethics BoardB. If you have any ethical concerns with the study, please contact Dr. Natasha Artemeva, 
Chair, Carleton University Research Ethics Board (by phone at 613-520-2600 [ext. 4085] or by email at ethics@carleton.ca).

\section{Statement of consent}

Click "I Agree" to indicate that you understand the information above and would like to participate in this study or "I Disagree" if you do not want to do the survey. 


\title{
Appendix I
}

\section{Debriefing Form}

\section{Carleton \\ U N I VER S I T Y \\ Canada's Capital University}

\section{Debriefing Form}

Name and Contact Information of Researchers: This study is led by Lynden Perrault (lyndenperrault@cmail.carleton.ca) under the supervision of Dr. Kevin Nunes (email: kevin.nunes@carleton.ca, phone: 613-520-2600, ext. 1545).

Project Title: A Study on Attitudes and Violent Behaviour

\section{Project Sponsor and Funder:}

Social Sciences and Humanities Research Council Insight Development Grant

\section{Carleton University Project Clearance}

\author{
Clearance \#: 111178 \\ Date of Clearance: August 9, 2019
}

\section{What Are We Trying to Learn in this Research?}

The purpose of this study is to test if evaluative attitudes towards violence influence violent behaviour. A third of participants got information about the positive consequences of violence, which was meant to make evaluations of violence more positive. The next third of participants got information about the negative consequences of violence, which was meant to make evaluations of violence more negative. The last third got information about the Grand Canyon, which was not meant to have any effect on evaluations of violence. If evaluations of violence influence violent behaviour, then responses to the conflict situations should be more violent for those with more positive evaluations of violence and less violent for those with negative evaluations of violence.

\section{Why Is This Important to Scientists or the General Public?}

Although evaluative attitudes have a demonstrated influence on general behaviour, evaluation of violence seems to have been largely overlooked in theory, research, and clinical practice (Nunes, Hermann, Maimone, \& Woods, 2015). To address this important gap, we are testing the link between evaluations of violence and violent behaviour to facilitate advances in research and practice that may ultimately contribute to reducing violence. 


\section{What are our hypotheses and predictions?}

We hypothesized that changing evaluations of violence would directly change the number of violent responses that a person makes to the conflict situations. As stated earlier, we predicted that more positive evaluations of violence would lead to more violent responses for the conflict situations and more negative evaluation would lead to fewer violent responses for the conflict situations.

\section{Where Can I Learn More?}

Please follow the link below for more information about violence from the American Psychological Association:

http://www.apa.org/topics/violence/

For information about evaluations of violence, click on the link below to a relevant conference presentation:

https://carleton.ca/acbrlab/wp-content/uploads/Nunes-2018-April-Violent-attitude-R-and$\underline{\text { R-conference-keynote-handout-2018-04-11.pdf }}$

For more information about our research in the Aggressive Cognitions and Behaviour Research Laboratory, click on the link below:

www.carleton.ca/acbrlab

\section{Is There Anything I Can Do if I Found This Experiment to be Emotionally Draining?}

If you experience any distress (e.g., feel sad or mad) as a result of this study, please refer to the information provided below for crisis hotlines and other support services:

Mental Health Today: http://www.mental-health-today.com/resources/toll.htm

Suicide prevention lifeline: 1-800-273-8255 (TALK) www.suicidepreventionlifeline.org/

Some resources in Canada: http://www1.carleton.ca/health/emergencies-and-

List of resources by country:

$$
\text { crisis/emergency-numbers/ }
$$

http://www.suicideforum.com/showthread.php?42096-Crisis-Hotline-Numbers$\underline{\text { International }}$

\section{What if I Have Questions Later?}

If you have any remaining concerns, questions, or comments about the experiment, please feel free to contact Lynden Perrault at lyndenperrault@ecmail.carleton.ca, or Dr. Kevin Nunes (Professor, Department of Psychology, Carleton University, by phone 613$520-2600$, ext 1545 or by email kevin.nunes@carleton.ca) 
If you have any ethical concerns with the study, please contact Dr. Natasha Artemeva, Chair, Carleton University Research Ethics Board (by phone at 613-520-2600 [ext. 4085] or by email at ethics@carleton.ca).

Thank you very much for making this research possible. 


\section{Appendix J}

Nature Scenes Presented After the Study to Enhance Mood
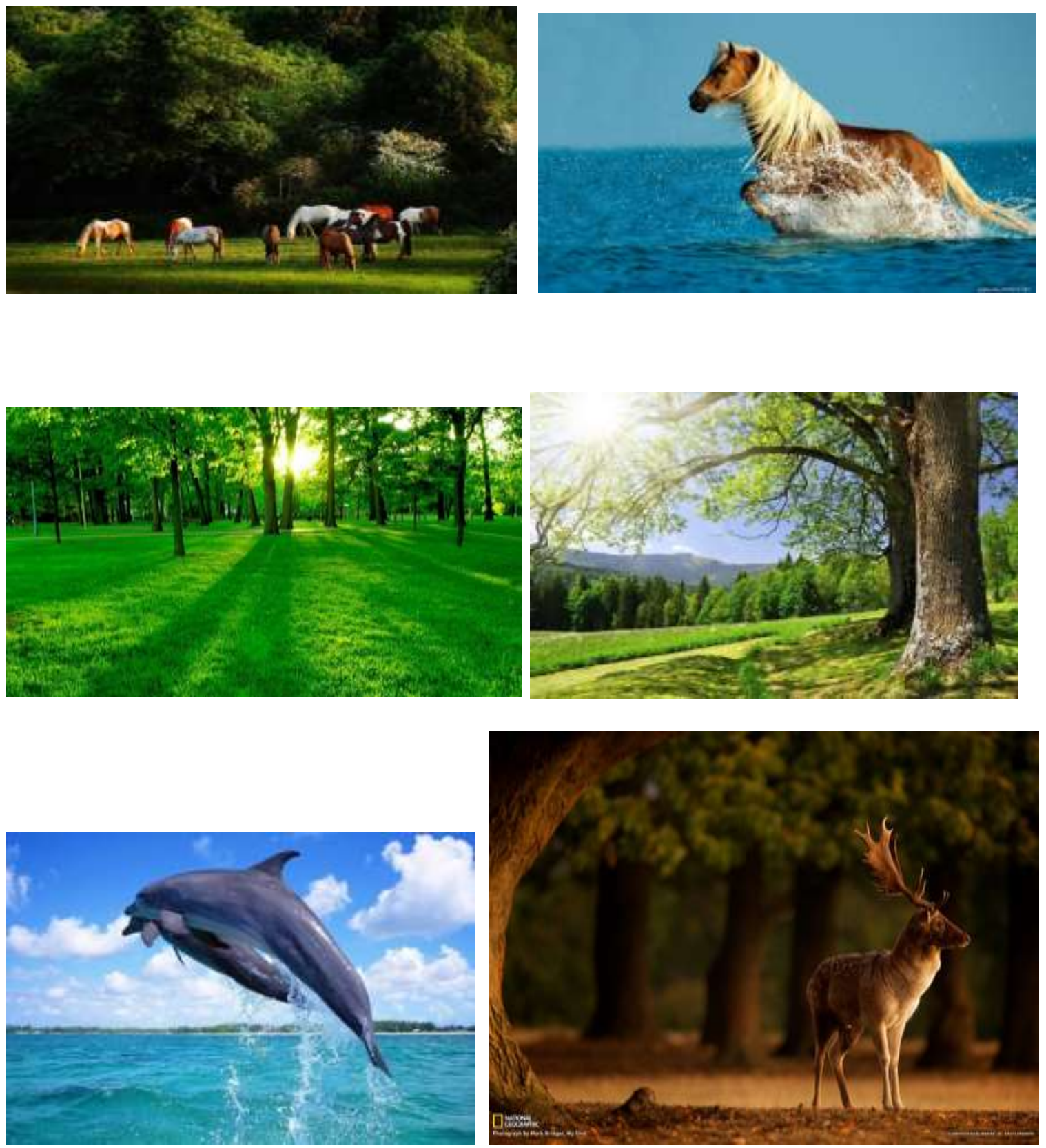

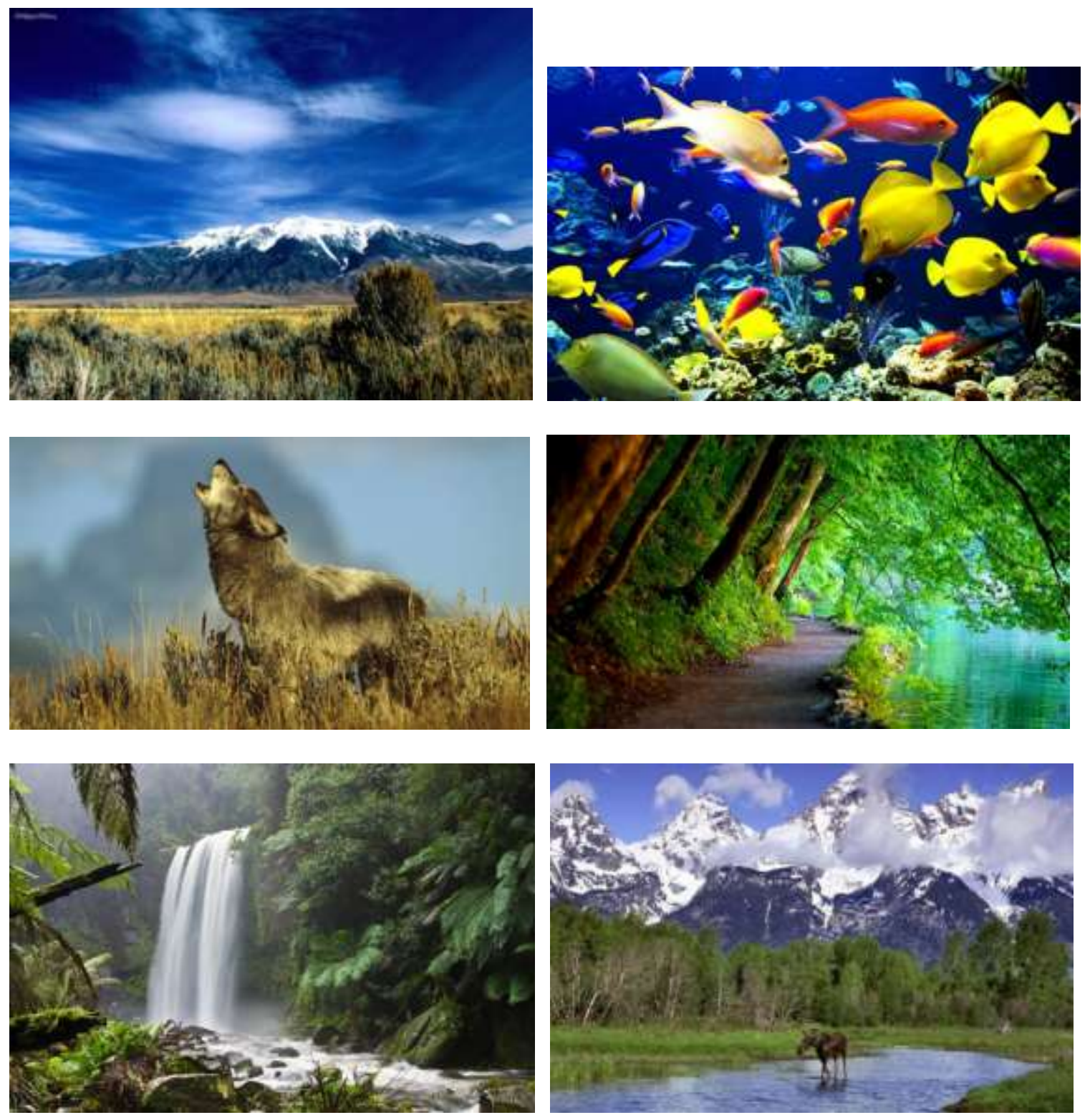


\section{Appendix K}

Descriptive Statistics for the EVQ and the VPVQ Contrasting the Entire Sample with the Men who Report Being Attracted to Women

\begin{tabular}{|c|c|c|c|c|c|}
\hline \multirow[b]{2}{*}{ Condition } & \multirow[b]{2}{*}{$n$} & \multicolumn{2}{|c|}{ EVQ } & \multicolumn{2}{|c|}{ VPVQ } \\
\hline & & $M(S D)$ & $95 \% \mathrm{CI}$ & $M(S D)$ & $95 \% \mathrm{CI}$ \\
\hline & \multicolumn{5}{|c|}{ Entire Sample } \\
\hline Anti-Violence & 175 & $2.05(0.66)$ & {$[1.96,2.15]$} & $2.42(2.66)$ & {$[2.02,2.81]$} \\
\hline Neutral & 176 & $2.29(0.74)$ & {$[2.17,2.40]$} & $3.23(2.92)$ & {$[2.79,3.66]$} \\
\hline \multirow[t]{2}{*}{ Pro-Violence } & 175 & $2.25(0.60)$ & {$[2.16,2.34]$} & $3.38(2.66)$ & {$[2.99,3.78]$} \\
\hline & \multicolumn{5}{|c|}{ Men Attracted to Women } \\
\hline Anti-Violence & 163 & $2.04(0.66)$ & {$[1.94,2.14]$} & $2.50(2.65)$ & {$[2.09,2.91]$} \\
\hline Neutral & 161 & $2.27(0.74)$ & {$[2.17,2.40]$} & $3.22(2.91)$ & {$[2.76,3.67]$} \\
\hline Pro-Violence & 163 & $2.26(0.60)$ & {$[2.18,2.36]$} & $3.50(2.66)$ & {$[3.09,3.91]$} \\
\hline
\end{tabular}

Note. VPVQ = Violence Propensity Vignette Questionnaire; EVQ = Evaluation of Violence Questionnaire; $\mathrm{M}=$ Mean; $\mathrm{SD}=$ Standard Deviation; $\mathrm{CI}=$ Confidence Interval. 


\section{Appendix L}

Descriptive Statistics for the EVQ and the VPVQ Contrasting the Entire Sample with the Men Who Reported Being Attracted to Women When Excluding Non-

\section{Genuine Responses}

\begin{tabular}{|c|c|c|c|c|c|}
\hline \multirow[b]{2}{*}{ Condition } & \multirow[b]{2}{*}{$n$} & \multicolumn{2}{|c|}{ EVQ } & \multicolumn{2}{|c|}{ VPVQ } \\
\hline & & $M(S D)$ & $95 \% \mathrm{CI}$ & $M(S D)$ & $95 \% \mathrm{CI}$ \\
\hline & \multicolumn{5}{|c|}{ Sensitivity Sample } \\
\hline Anti-Violence & 149 & $1.99(0.64)$ & {$[1.89,2.10]$} & $2.31(2.62)$ & {$[1.88,2.73]$} \\
\hline Neutral & 176 & $2.29(0.74)$ & {$[2.17,2.40]$} & $3.23(2.92)$ & {$[2.79,3.66]$} \\
\hline \multirow[t]{2}{*}{ Pro-Violence } & 139 & $2.22(0.62)$ & {$[2.11,2.32]$} & $3.30(2.60)$ & {$[2.86,3.73]$} \\
\hline & \multicolumn{5}{|c|}{ Men Attracted to Women } \\
\hline Anti-Violence & 139 & $1.98(0.64)$ & {$[1.87,2.09]$} & $2.41(2.65)$ & {$[1.97,2.86]$} \\
\hline Neutral & 161 & $2.28(0.74)$ & {$[2.17,2.40]$} & $3.22(2.91)$ & {$[2.76,3.67]$} \\
\hline Pro-Violence & 131 & $2.24(0.61)$ & {$[2.13,2.35]$} & $3.39(2.60)$ & {$[2.94,3.84]$} \\
\hline
\end{tabular}




\section{Appendix M}

Negative Binomial Regression Analyses Only Including Men Who Reported Being Attracted to Women

\begin{tabular}{|c|c|c|c|c|}
\hline Condition & $B$ & $S E$ & $\operatorname{Exp}(B)$ & $95 \% \mathrm{CI}$ \\
\hline & \multicolumn{4}{|c|}{ Full Sample } \\
\hline Anti-Violence ${ }^{a}$ & $-0.25^{*}$ & 0.12 & 0.78 & {$[0.62,0.97]$} \\
\hline Pro-Violence ${ }^{\mathrm{a}}$ & 0.08 & 0.11 & 1.09 & {$[0.87,1.35]$} \\
\hline \multirow[t]{2}{*}{ Anti-Violence $^{\mathrm{b}}$} & $-0.34 * *$ & 0.11 & 0.71 & {$[0.74,1.15]$} \\
\hline & \multicolumn{4}{|c|}{ Sensitivity Analysis } \\
\hline Anti-Violence ${ }^{a}$ & $-0.29 *$ & 0.12 & 0.75 & [0.59. 0.96] \\
\hline Pro-Violence ${ }^{\mathrm{a}}$ & 0.05 & 0.12 & 1.05 & {$[0.83,1.33]$} \\
\hline Anti-Violence ${ }^{b}$ & $-0.34 * *$ & 0.13 & 0.71 & {$[0.75,1.20]$} \\
\hline $\begin{array}{l}\text { Note. } \mathrm{CI}=\text { Confi } \\
{ }^{\mathrm{a}} \text { Neutral conditio } \\
{ }^{\mathrm{b} P r o-v i o l e n c e} \mathrm{gr} \\
{ }^{*} p<.05 \\
* * p<.01\end{array}$ & $\begin{array}{l}\text { e Interval } \\
\text { signated a } \\
\text { lesignatec }\end{array}$ & $\begin{array}{l}\mathrm{olgc} \text { gro } \\
\text { trol g }\end{array}$ & & \\
\hline
\end{tabular}

